\title{
An Experimental Study of Costly CoORdination
}

\author{
Jacob K. Goeree and Charles A. Holt \\ Department of Economics, Rouss Hall, University of Virginia, Charlottesville, VA 22903
}

\begin{abstract}
This paper reports data for coordination game experiments with random matching. The experimental design is based on changes in an effort-cost parameter, which do not alter the set of Nash equilibria, nor do they alter the predictions of dynamic adjustment theories based on imitation or best responses to others' decisions. As would be expected, however, increases in effort cost result in reduced effort levels. Average behavior in the final periods is consistent with a one-parameter stochastic generalization of the Nash equilibrium that is calculated by maximizing a "stochastic potential function." The noise parameter estimated from the initial twoperson, minimum-effort games is used to predict behavior in subsequent experiments with threeperson games, using both minimum and medium-effort payoff structures.
\end{abstract}

JEL Classification: C72, C92.

Keywords: coordination games, laboratory experiments, stochastic potential, logit equilibrium. 


\title{
An Experimental Study of Costly Coordination
}

\author{
Jacob K. Goeree and Charles A. Holt
}

\section{INTRODUCTION}

After the prisoner's dilemma, the coordination game is perhaps the most widely discussed paradigm in game theory. Interest in coordination games stems from the presence of multiple Nash equilibria that can be Pareto ranked, which raises the possibility of "getting stuck" in an outcome that is undesirable for all players. For this reason, this class of games is of interest to macroeconomists (Bryant, 1983; Cooper and John, 1988; and Romer, 1996). Since (generically) all equilibria are strict, standard refinements leave the set of Nash equilibria unchanged, which has prompted game theorists to search for new selection criteria. An array of alternative theories of behavior in coordination games have been put forward, both static and dynamic. Static approaches include Pareto dominance (Harsanyi and Selten, 1988), risk dominance (Harsanyi, 1995; Carlsson and van Damme, 1993), and "noisy" equilibrium models (Anderson, Goeree, and Holt, 1997b; Carlsson and Ganslandt, 1998). Dynamic models of coordination behavior can be roughly divided into evolutionary models (Kandori, Mailath, and Rob, 1993; Young, 1993; Crawford, 1991), adaptive learning models (Crawford, 1995; Van Huyck, Battalio, and Rankin, 1995), and "noisy" learning models (Battalio, Samuelson, and Van Huyck, 1997; Camerer and Ho, 1999).

Some theorists argue that coordination game experiments are useless for game theory because the Nash equilibrium and its refinements have no predictive power in this case and, as a consequence, "anything goes." We feel that the opposite is true: the unexpected empirical regularities observed in coordination experiments (such as the ones reported in this paper) can guide further theoretical work. For instance, previous experiments have shown that coordination problems cannot be ruled out by an assumption that agents somehow find the Pareto-dominant equilibrium. Indeed, some of the most widely cited results from laboratory experiments provide cases where subjects end up at the Nash equilibrium that is worst for all concerned (Van Huyck, Battalio, and Beil, 1990; Cooper et al., 1992; and the survey in Ochs, 1995). Since much of the theoretical work was motivated by the need to explain coordination failures in the laboratory, it

\footnotetext{
This project was funded in part by the National Science Foundation (SBR-9818683). We wish to thank Vince Crawford and Robert Rosenthal for useful discussion and Rachel Parkin for research assistance.
} 
is now time to return to return to the laboratory and carry out experiments designed explicitly to evaluate some of these theories.

This paper reports the results of several new coordination experiments motivated by both static and dynamic models of behavior in coordination games. The first game to be considered is one in which pairs of subjects choose an effort level, and the resulting payoff is the minimum of the efforts minus the cost of one's own effort. This payoff structure can arise from a joint production process in which the group output is proportional to the minimum of the individual inputs, as is the case with perfect complementarity. The different treatments are based on a change in the common cost per unit of effort. As long as this cost is less than one, the best response to any set of others' efforts is just the minimum of those efforts, so (non-critical) changes in the cost of effort will not alter the set of Nash equilibria in pure strategies, nor will they change the predictions of any dynamic theory that is based on adjustment toward the best response to efforts observed in the previous period. Changes in the cost of effort do affect the relative costs of "errors" in overshooting or undershooting the minimum of other's efforts, so theories like risk dominance and maximum potential (discussed below) that take into account the costs of errors will be sensitive to the effort cost parameter.

The data of this first experiment allow us to test and calibrate an equilibrium model of noisy behavior. This equilibrium results by maximizing a stochastic potential function and can be seen as a one-parameter stochastic generalization of the Nash equilibrium. To get a sense for how robust this approach is, we estimate the relevant parameter using data from the six sessions with two-person coordination games and use this estimate for "out-of-sample" prediction in seven new sessions with three-person games. These new sessions include both minimum-effort and median-effort coordination games.

The paper is organized as follows: the theoretical motivation for the experimental design is discussed in more detail in section 2 , and section 3 presents the laboratory results. The notion of stochastic potential is introduced in section 4, and is related to the notion of a logit equilibrium (McKelvey and Palfrey, 1995). Section 5 reports experiments based on three-person median and minimum-effort games. The final section concludes, and a set of instructions and the laboratory data can be found in the Appendices. 


\section{Pareto Dominance, Risk Dominance, and Maximum Potential}

The experiment involves a series of single-period coordination games with groups of randomly matched subjects who make independent "effort" choices. Subjects selected efforts from a continuous interval $[\underline{e}, \bar{e}]$, i.e. fractional efforts were allowed. We first review some standard theoretical results for this game in order to motivate the choice of treatment parameters. Let the effort for player $i$ be denoted by $e_{\mathrm{i}} \in[\underline{e}, \bar{e}], i=1, \ldots, n$. The payoffs for a symmetric, $n$ person minimum-effort game are:

$$
\pi_{i}\left(e_{1}, \ldots, e_{n}\right)=\min \left\{e_{1}, \ldots, e_{n}\right\}-c e_{i}, \quad i=1, \ldots, n
$$

where $c$ is the effort cost. As long as $c$ is less than 1, payoffs are maximized when all players choose the highest possible effort. ${ }^{1}$ Note, however, that any common effort level constitutes a Nash equilibrium, since a costly unilateral increase in effort will not raise the minimum, and a unilateral decrease will reduce the minimum by more than the cost when $c<1$. This argument does not depend on the number of players, so non-critical changes in $c$ and $n$ will not alter the set of Nash equilibria in pure strategies, despite the reasonable expectation that efforts should be high for sufficiently low effort costs and low numbers of participants. ${ }^{2}$

Harsanyi and Selten's (1988) notion of risk dominance is sensitive to the effort cost that determines the losses associated with deviations from best responses to others' decisions. To illustrate the concept of risk dominance, consider the two-person minimum-effort game shown in Figure 1 in which efforts are constrained to be the integers 1 or 2 . When both players are choosing efforts of 1 , the cost of a unilateral deviation to 2 is just the cost of the extra effort, $c$, which will be referred to as the "deviation loss." Similarly, the deviation loss at the $(2,2)$ equilibrium is $1-c$, since a unilateral reduction in effort reduces the minimum by 1 but saves the marginal effort cost $c$. The deviation loss from the low-effort equilibrium is greater than that for

1 If the minimum effort in (1) is multiplied by a constant $\alpha$, as is the case in some laboratory experiments, then the relevant value of $c$ is the effort cost divided by $\alpha$. Although we normalize so that $\alpha=1$, this observation is relevant in considering the implications of risk dominance for experiments where this is not the case.

2 Anderson, Goeree, and Holt (1997b) show that there are a continuum of (two-point) mixed Nash equilibria, but that each of these has the perverse comparative statics property that an increase in the effort cost will raise the probability associated with the higher of the two effort levels over which randomization occurs. 
the high-effort equilibrium if $c>1-c$, or equivalently, if $c>1 / 2$, in which case we say that the low-effort equilibrium is risk dominant. ${ }^{3}$ Risk dominance, therefore, has the desirable property that it selects the low-effort outcome if the cost of effort is sufficiently high.

Player 2's Effort

\begin{tabular}{|c|c|c|c|}
\hline \multirow{3}{*}{$\begin{array}{c}\text { Player 1's } \\
\text { Effort }\end{array}$} & & 1 & 2 \\
\hline & 1 & $1-c, 1-c$ & $1-c, 1-2 c$ \\
\hline & 2 & $1-2 c, 1-c$ & $2-2 c, 2-2 c$ \\
\hline
\end{tabular}

Figure 1. A $2 \times 2$ Coordination Game

There is, however, no consensus on how to generalize risk dominance for games with more players, a continuum of decisions, etc. A related concept that does generalize is the notion of maximization of a "potential" of a game. ${ }^{4}$ Loosely speaking, the idea behind potential is to find a function for a game that is maximized by a Nash equilibrium for that game. More precisely, a potential function for a game is a function of all players' decisions with partial derivatives that match those of individual players' payoffs with respect to their own decisions. For example, it is straightforward to show that the potential function for the $2 \times 2$ coordination game in Table I is given by: $V=p_{1} p_{2}-(1-c)\left(p_{1}+p_{2}\right)$, where $p_{\mathrm{i}}$ denotes the probability with which player $i$ chooses the low effort $1 .^{5}$ Hence, the potential is maximized in the low-effort outcome $\left(p_{1}=p_{2}=1\right)$ when $c>1 / 2$ and it is maximized in the high-effort outcome $\left(p_{1}=p_{2}=0\right)$ when $c<1 / 2$. For the $2 \times 2$ coordination game shown in Table I, risk-dominance and maximum potential thus coincide, and one can easily show that this equivalence holds for all symmetric 2 $\times 2$ games. Laboratory experiments based on $2 \times 2$ coordination games show that the risk dominant/maximum potential outcome has a lot of drawing power when the difference in

3 The application of risk dominance for asymmetric two-person games is equivalent to comparing the product of the two players' deviations losses at each equilibrium.

4 Rosenthal (1973) first used a potential function to study properties of a Nash equilibrium. Monderer and Shapley (1996) provide a general treatment.

5 Player $i$ 's payoff of choosing the low effort with probability $p_{\mathrm{i}}$ is: $\pi_{\mathrm{i}}\left(p_{\mathrm{i}}, p_{\mathrm{j}}\right)=p_{\mathrm{i}} p_{\mathrm{j}}-p_{\mathrm{i}}(1-c)-p_{\mathrm{j}}+(2-2 c)$, and it is straightforward to check that $\partial V_{\mathrm{i}} / \partial p_{\mathrm{i}}=\partial \pi_{\mathrm{i}} / \partial p_{\mathrm{i}}$ for $i=1,2$. 
potential is large, even though play usually starts out near the Pareto-dominant equilibrium for which the payoffs may be much higher (see Table 4 in Battalio, Samuelson, and Van Huyck, 1997; see also Straub, 1995).

However, as noted above, risk-dominance does not apply to more general settings while the notion of maximum potential does. For instance, for the $n$-player minimum effort game given in (1), the potential function is simply the common production function that determines a single player's payoff, minus the sum of all players' effort costs:

$$
V\left(e_{1}, \ldots, e_{n}\right)=\min \left\{e_{1}, \ldots, e_{n}\right\}-c \sum_{i=1}^{n} e_{i} .
$$

The inclusion of all effort costs is needed to ensure that $\partial V_{\mathrm{i}} / \partial e_{\mathrm{i}}=\partial \pi_{\mathrm{i}} / \partial e_{\mathrm{i}}, i=1, \ldots, n$, for all feasible vectors of decisions, when these derivatives exist. The maximization of potential will obviously require equal effort levels. At any common effort, $e$, the potential in (2) becomes: $V=e-n c e$, which is maximized at the lowest effort when $n c>1$, and is maximized at the highest effort when $n c<1$. In two-person games, this condition reduces to the risk dominance comparison of $c$ with $1 / 2$. Hence, the Nash equilibrium that maximizes potential in this game is sensitive to parameters that may affect actual behavior.

The notion of potential can be used to evaluate results from previous laboratory experiments. The most widely cited coordination experiment is that of Van Huyck, Battalio, and Beil (1990), who conducted games with 14 to 16 players and an effort cost of either 0 or $1 / 2$, so $n c$ was either zero or about seven. ${ }^{6}$ Compared to the critical $n c$ value of 1 , these parameter choices appear rather extreme, which may explain why their data exhibit a huge shift in effort decisions. By the last round in the experiments in which $n c=0$, almost all (96\%) participants chose the highest possible effort, while over three-quarters chose the lowest possible effort when $n c$ was around seven. One purpose of Van Huyck, Battalio, and Beil's experiment was to show that a Pareto-inferior outcome may arise in coordination games, presumably because it is harder for large numbers of participants to coordinate on good outcomes in games where the payoff is

6 The minimum effort in the experiment was multiplied by a constant, which is normalized to be 1 in equation (1) above. Therefore, the relevant value of $c$ for the experiment is calculated as the ratio of the cost of effort and the coefficient of the minimum effort. 
determined by the minimum of all efforts. Other experiments were conducted with 2 players, but the payoff parameters were such that $n c$ exactly equaled the critical value 1 , and, with a random matching protocol, the data showed a lot of variability. ${ }^{7}$ Our experiment also implements two-person random matchings in order to avoid serious possibility of tacit collusion in repeated games, which may drive efforts to maximal levels in sufficiently long series of repeated two-person coordination games. Given the knife-edge properties of $c=1 / 2$ for twoperson coordination games, we conducted one treatment with $c=1 / 4$ and another with $c=3 / 4$. As noted above, this change does not alter the predictions of theories based on best responses to others' decisions, e.g. pure-strategy Nash equilibria.

\section{THE EXPERIMENT}

Recall that one purpose of our experiment is to generate conditions such that behavior is "non-extreme," i.e. find conditions under which decisions do not necessarily end up at the boundaries. One step in this direction is to have more than just a few possible effort levels. Therefore, we let subjects choose from a continuous interval: $[110,170]$. We chose this particular range with the object of avoiding a highly focal number like 50 or 100, and we did not want 150 to be at the midpoint of the range. ${ }^{8}$ Furthermore, this choice facilitates the comparison of our results with those of Van Huyck, Battalio, and Beil (1990) who let subjects choose integer effort levels that ranged from 1 to 7.

The experimental design involved six sessions, each with 10 student subjects recruited from undergraduate economics classes at the University of Virginia. No subject had previously participated in a coordination game. Upon arrival, participants were seated in visually isolated booths. We began by reading the instructions in Appendix A. The payoffs were explained in words and with symbols, e.g.: "you will receive a penny amount that equals the minimum of the two efforts chosen, minus the cost of your own effort, which is .25 times your own effort choice." There were no numerical examples in the instructions, in order to avoid focal

7 When subjects were matched with the same partner period after period the data often converged to the maximum effort.

8 Although focalness plays no role in our theory, we believe that it can be important, especially in coordination games. 
suggestions. Questions were asked and answered privately to avoid suggestive statements.

Subjects were told that there would be 10 periods of random pairings determined by draws of numbered ping-pong balls from a bucket. The noise of ping-pong draws probably made this random matching procedure more credible. At the start of each period, subjects were prompted to record an effort decision and write it on a record sheet provided. The range of feasible effort choices was specified to be the interval [110, 170], with fractional efforts allowed, which they could select by using decimal points. We then collected the record sheets, paired subjects, and recorded the "other person's decision" and the person's own earnings. The sheets were returned at the beginning of the next period. The process took about one hour. ${ }^{9}$

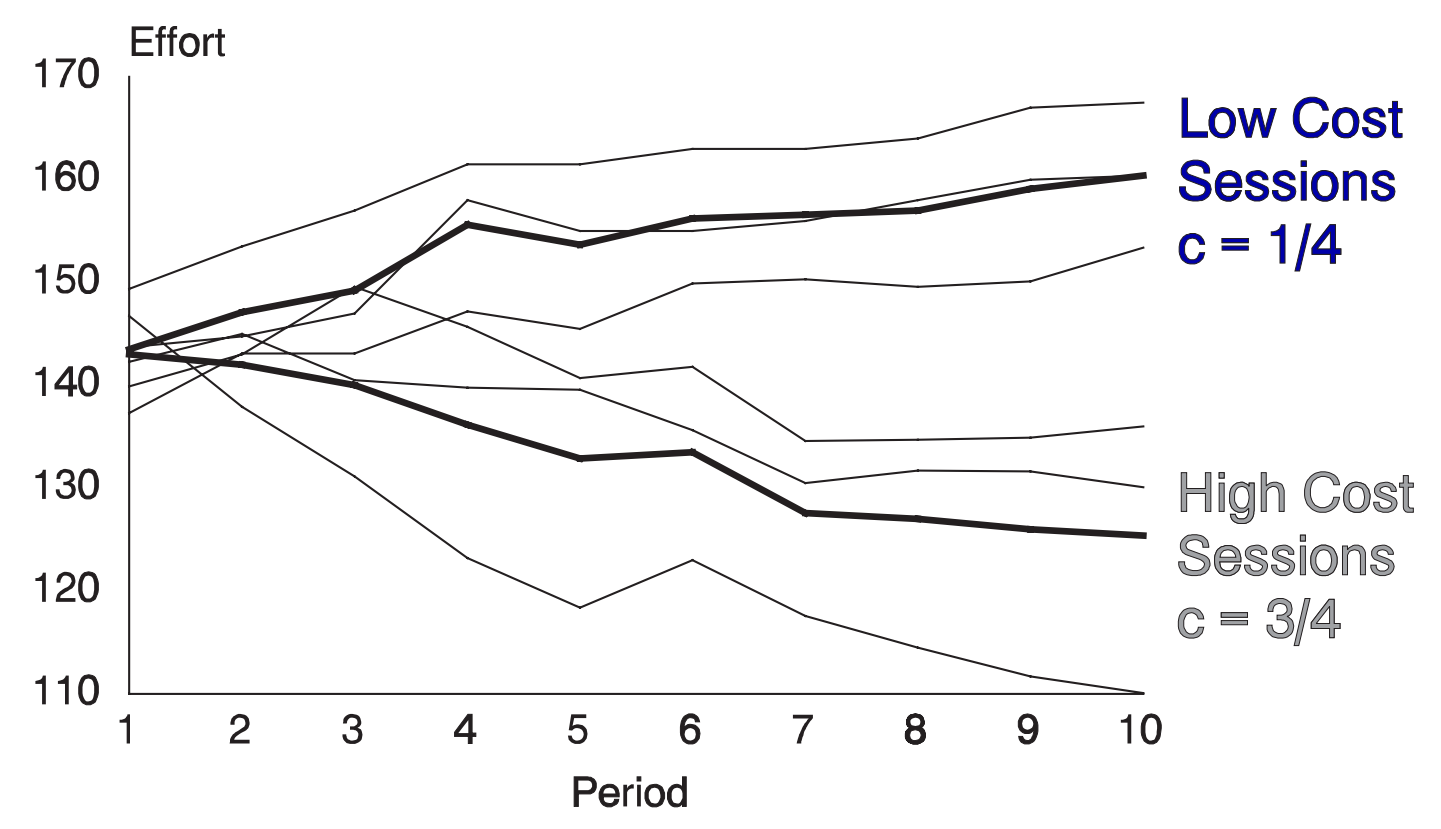

Figure 2. A Coordination Game: Average Effort Decisions by Period

Key: Dashed lines are session averages. Dark lines are averages across all sessions in a treatment.

Three sessions were conducted under the high-cost treatment $(c=3 / 4)$ and three under

9 The instructions stated that the 10 periods of random matching would be followed by "a different experiment." In fact, these two-person coordination games were followed by a series of 6-9 one-period games of chicken, matching pennies, etc. 
the low-cost treatment $(c=1 / 4) .{ }^{10}$ The period-by-period averages for each session are shown as thin lines in Figure 2, and the averages for all sessions in each treatment are shown as thick lines. The data exhibit a couple of interesting features. First, the averages of all sessions begin near the midpoint of the range of feasible effort choices on the vertical axis. Figure 3 shows the histograms of the effort decisions in the first and in the last three periods for the high-cost treatment (light) and low-cost treatment (dark). For both values of the effort cost, the null hypothesis that the initial distributions are equal to a uniform distribution cannot be rejected at the 10 percent level using a standard Kolmogorov-Smirnov test. ${ }^{11}$ Second, even though all sessions start out similarly, a clear separation is apparent by the fifth period. For later periods, the null hypothesis of no treatment effect can be rejected at the 5 percent level of significance using a non-parametric test. ${ }^{12}$ In the last three periods, all decisions in the low-cost sessions are above the midpoint (140), while almost all decisions are below the midpoint with a high cost, as shown in Figure 3. Finally, the average effort trajectories seem to spread symmetrically around the midpoint: the upward trend for the three low-effort-cost sessions is reflected by an essentially symmetric downward trend for the three high-effort-cost sessions. To summarize the main findings: a change in the effort cost has a large and significant effect on behavior in the minimum-effort coordination game, an effect that is not predicted by the Nash equilibrium.

The strong treatment effect that is driving the data is simply not predicted in a Nash equilibrium, nor do the data converge to extreme values as would be implied by maximum potential. There is usually some noise in laboratory data with non-extreme payoff parameters,

10 This created somewhat of a dilemma, since earnings are much lower under the high-cost treatment. We dealt with this issue by increasing the fixed payment from the customary level of $\$ 6$ to a level, $\$ 12$, that would ensure reasonable earnings for the first hour, even for the high-cost treatment. (The \$6 initial payment was used in session 1 , with the low-effort-cost treatment, but the higher initial payment was used in all subsequent sessions.) Including the fixed payment, most subjects' earnings were in the $\$ 7$ to $\$ 9$ range in 0.25 treatment, and in the $\$ 16$ to $\$ 18$ range in the 0.75 treatment. These earnings were augmented in the one-period games that followed.

11 Comparing the empirical distribution functions with a uniform distribution results in a Kolmogorov-Smirnov statistic of .2 for both treatments, while the critical value is .22 for a sample size of 30 and a confidence level of 10 percent. The null hypothesis that the first-period empirical distributions for the two treatments are the same cannot be rejected at much higher levels.

12 The intuition behind the test is clear. There are "six-take-three" $=20$ possible ways that the effort averages could have been ranked, and of these the most extreme ranking was observed, with all three low- $c$ sessions having the highest ranks. The probability of this outcome under the null is, therefore, $1 / 20=0.05$. 

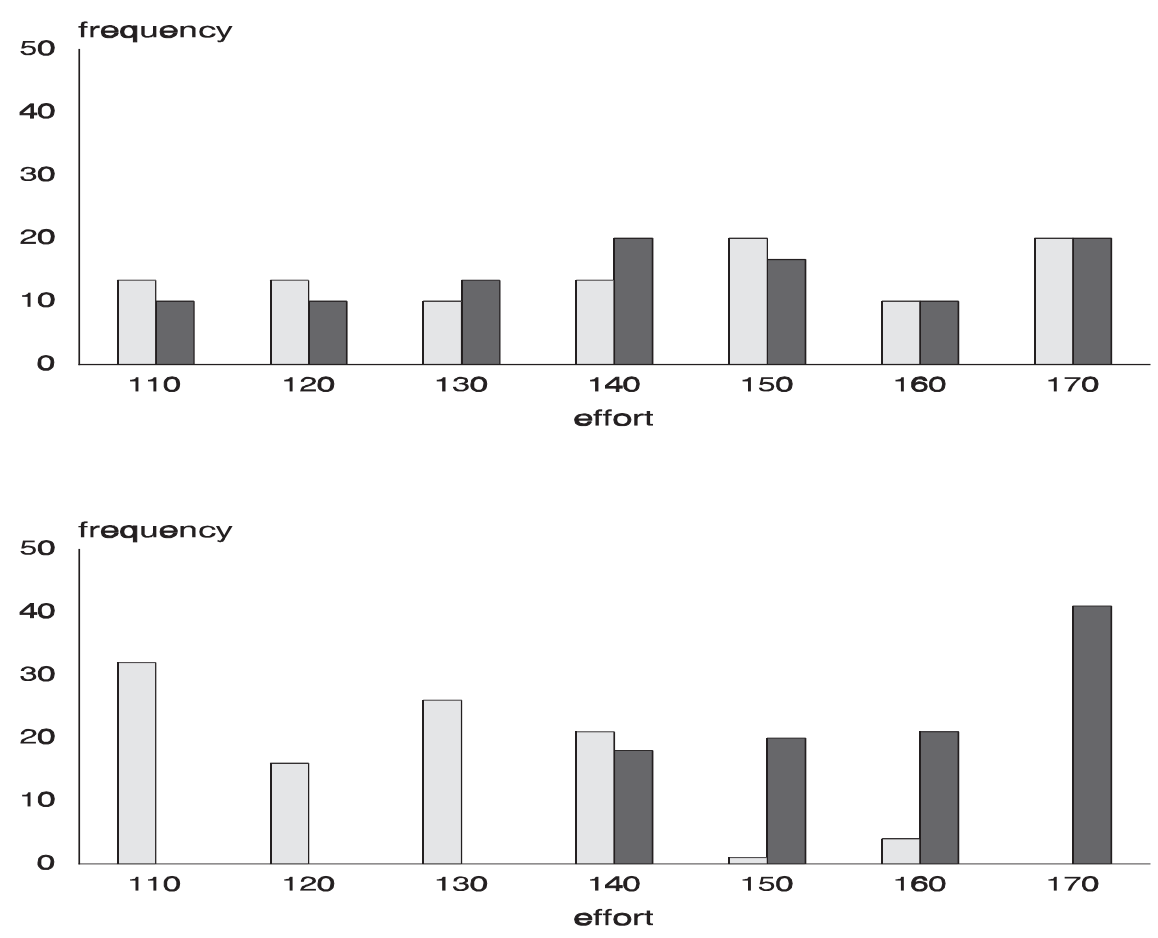

Figure 3. Effort Choice Frequencies in Period 1 (Top) and Periods 8 - 10 (Bottom) Key: Light Bars Correspond to High Effort Cost and Dark Bars to Low Effort Cost

and to deal with this it is useful to consider notions of noisy behavior. The next section introduces a generalization of potential that is related to a noisy version of the Nash equilibrium.

\section{Stochastic Potential And the Logit EQUilibrium}

If a game has a potential function $V$, the stochastic potential is based on a consideration of probability distributions of decisions that determine the expected value of potential (Anderson, Goeree, and Holt, 1997). In particular, the stochastic potential for given distributions of players' decisions is the expected value of the ordinary potential, denoted $\mathrm{E}\{V\}$, plus terms that will make the maximand sensitive to noise in the choice distributions. These terms that determine the value of dispersion correspond to the physical concept of "entropy." In the case of a continuous 
density function, $f_{\mathrm{i}}\left(e_{\mathrm{i}}\right)$, entropy is defined as: $-\int f_{\mathrm{i}} \ln \left(f_{\mathrm{i}}\right) \mathrm{d} e_{\mathrm{i}} .{ }^{13}$ The entropy for the system is the sum of the entropy terms for individual players' distributions, weighted by an error parameter $\mu$. Thus the stochastic potential is: $\mathrm{E}\{V\}-\mu \Sigma_{\mathrm{i}} \int f_{\mathrm{i}} \ln \left(f_{\mathrm{i}}\right) \mathrm{d} e_{\mathrm{i}}$, where the sum is over all player indices and the integral is over the range of feasible effort choices. Since entropy is maximized by complete randomness (a uniform distribution of decisions), the distribution that maximizes expected potential plus $\mu$ times entropy will be more dispersed as the error parameter increases. In the other limit as $\mu \rightarrow 0$, the entropy term becomes irrelevant and the maximization of stochastic potential becomes equivalent to the maximization of ordinary potential, which leads to a Nash equilibrium in this context. Thus the maximization of stochastic potential provides a generalization of Nash that is parameterized by an error parameter $\mu$. In the remainder of this section, we will determine the predicted effort distributions for each of the values of the treatment variable $c$.

For the case of two players, the expected value of the potential function in (2) contains a term that is the expected value of the minimum of two decisions. If player $i$ uses a continuous choice density $f_{\mathrm{i}}\left(e_{\mathrm{i}}\right)$, with corresponding distribution function $F_{\mathrm{i}}\left(e_{\mathrm{i}}\right)$, then the distribution function for the minimum of the two effort decisions is: $1-\left(1-F_{1}\left(e_{1}\right)\right)\left(1-F_{2}\left(e_{2}\right)\right){ }^{14}$ The stochastic potential, $V_{S}$, is calculated by adding weighted entropy terms to the expected value of the minimum and subtracting the expected effort costs: ${ }^{15}$

$$
V_{S}=\int_{\underline{e}}^{\bar{e}} \prod_{i=1}^{2}\left(1-F_{i}(e)\right) d e-c \sum_{i=1}^{2} \int_{\underline{e}}^{\bar{e}}\left(1-F_{i}(e)\right) d e-\mu \sum_{i=1}^{2} \int_{\underline{e}}^{\bar{e}} f_{i}(e) \log \left(f_{i}(e)\right) d e .
$$

Anderson, Goeree, and Holt (1997b) show that maximization of the stochastic potential requires symmetry across players, i.e. $F_{1}(e)=F_{2}(e)=F(e)$, as is the case without noise. Maximization

13 In a more commonly considered discrete case, entropy is $-\Sigma_{\mathrm{i}} p_{\mathrm{i}} \ln \left(p_{\mathrm{i}}\right)$, where the $p_{\mathrm{i}}$ are the probabilities of the discrete outcomes.

14 This formula can be found in standard treatments of order statistics, or it can be verified directly since the probability that the minimum is below a given value of $x$ is 1 minus the probability that both efforts are above $x$, which yields the formula in the text.

15 Recall that the expected value of a random variable with distribution function $F$ can be written as the integral of $1-F$ (ignoring possible boundary terms that are independent of $F$ ). 
of the stochastic potential with respect to the common distribution $F(e)$ is a straightforward calculus-of-variations problem, and the necessary condition can be expressed: ${ }^{16}$

$$
\mu f^{\prime}(e)=f(e)(1-F(e)-c),
$$

which is a differential equation in the common distribution function.

Consider the intuition behind (4). If the other player is using an effort distribution, $F(e)$, then an increase in effort at $e$ will raise the minimum with probability $1-F(e)$ and increase the cost at a rate $c$, so the $1-F(e)-c$ term is the derivative of the expected payoff with respect to one's own effort. Hence, equation (4) can also be written as: $\mu f^{\prime}(e)=\pi^{\mathrm{e}^{\prime}}(e) f(e)$, which defines the continuous version of the "logit equilibrium" (McKelvey and Palfrey, 1995). ${ }^{17}$ Anderson, Goeree, and Holt (1997b) show that a solution to (4) exists, is unique, and that an increase in the effort cost lowers efforts in the sense of first-degree stochastic dominance. ${ }^{18,}$ Thus the prediction of this stochastic-potential approach is consistent with the intuitive notion that reductions in the effort cost will increase efforts, although not necessarily all the way to the maximum possible effort.

We used data from the coordination experiment to estimate the equilibrium model in (4)

16 Recall that the Euler condition for maximizing $\int \mathrm{I}(F, f, x) \mathrm{d} x$ is: $\delta \mathrm{I} / \delta \mathrm{F}=\partial \mathrm{I} / \partial F-\mathrm{d} / \mathrm{d} x\{\partial \mathrm{I} / \partial f\}=0$, or in the present context: $-2(1-F)+2 c+2 \mathrm{~d} / \mathrm{d} x\{\mu+\mu \ln f\}=-2(1-F-c)+2 \mu f^{\prime} / f=0$, where $f^{\prime}$ denotes the derivative of the density function. This result can be rearranged to obtain the expression in (4).

17 As the error parameter goes to infinity, the marginal payoff becomes irrelevant and the solution to (4) will have a flat density, i.e. $f^{\prime}(e)=0$, which yields a uniform effort distribution. As the error parameter goes to 0, equation (4) implies that marginal payoff is zero whenever $f(e)$ is positive. This in turn requires that $F(e)$ be constant at $1-c$, which is contradicted if the density is positive on an interval, i.e. the only possibility is that all mass is concentrated at a single point in the limit (at one of the common-effort Nash equilibria).

18 In fact, the differential equation (4) can be solved explicitly to obtain a logistic density.

19 We will use the concepts of logit equilibrium and maximization of stochastic potential interchangeably, although they differ in a subtle way. In particular, the variational condition in (4) is a first-order condition, and therefore, a logit equilibrium may be a local minimum of the stochastic potential. Anderson, Goeree, and Holt (1997a) show that local minima are unstable for a dynamic gradient-based adjustment process with Brownian motion, whereas local maxima are stable. Since we have proved that the logit equilibrium is unique for this game (Anderson, Goeree, and Holt, 1997b), it is globally stable for the evolutionary adjustment process. Incidentally, the noisy evolutionary adjustment process explains the symmetric adjustment patterns in Figure 2 (see Goeree and Holt, 1999). It is worth noting that there is a one-to-one correspondence between logit equilibria and extreme points of stochastic potential, whereas this equivalence does not hold for the twin concepts of the Nash equilibrium and (deterministic) potential. For example, there is a continuum of Nash equilibria for the coordination game, but only one maximizes potential when $c n \neq 1 / 2$. 
directly, by dividing the interval $[110,170]$ into one-cent intervals and replacing the density function in (4) with probabilities. ${ }^{20}$ Thus (4) becomes a set of simultaneous equations that determine the equilibrium probabilities for each effort level, and for a given value of $\mu$ the equations in (4) can be solved using numerical methods. The likelihood is the product of the calculated probabilities of the decisions actually observed and is maximized by iterating over $\mu$. This yields an estimated value of $\mu=7.4(0.3)$, with the standard error in parentheses. ${ }^{21}$

Table I. Average Effort Levels in Periods 8-10 (Standard Deviations)

\begin{tabular}{lccccc}
\hline \hline & session 1 & session 2 & session 3 & Pooled & Logit Equilibrium \\
\cline { 2 - 5 } low cost $(c=1 / 4)$ & $151(10)$ & $166(5)$ & $159(12)$ & $159(11)$ & $154(12)$ \\
high cost $(c=3 / 4)$ & $131(11)$ & $112(5)$ & $135(11)$ & $126(14)$ & $126(12)$ \\
\hline
\end{tabular}

Table I shows the average effort levels (standard deviations) in the final three periods by session and pooled over all three sessions in each treatment. For both values of the effort cost, two of the three session averages are within one standard deviation of the average predicted by the logit equilibrium that maximizes stochastic potential. There are, however, unexplained differences between different sessions in the same treatment (cohort effects). Consider, for instance, session 2 of the high-cost treatment, in which initial behavior in the first three periods is more extreme than in the other high-cost sessions. Subsequent effort choices are lower and

20 Clearly, the data show some systematic time patterns in the early periods, which is why we only used the last three periods to estimate the equilibrium value of $\mu$.

21 The error parameter estimate is of the same magnitude as other equilibrium error rates for different games with similar procedures and subjects, e.g. Capra, et al. (1999). This error rate, however, is higher than the $\mu$ estimates that we obtained by directly estimating a dynamic learning model based on fictitious play (not reported here). The higher $\mu$ estimate for the equilibrium model is mainly due to "between sessions" variance (rather than "within sessions" variance): the final-period averages differ significantly between sessions within the same treatment, and only a relatively large error parameter is consistent with the combined data. This cohort effect is less of a problem for the dynamic model which allows for history dependence: for example, higher-than-average effort choices in the final periods can be consistent with a low error rate when they are caused by optimistic beliefs due to high effort choices in the early periods. It is in this sense that a learning model can describe the (individual) data better than an equilibrium model, although both explain the cost effects that are not predicted by the Nash equilibrium. Learning models that use data up to period $t$ to predict outcomes in the next period will generally have lower prediction errors than equilibrium models that are intended to predict where decisions will settle down after learning has occurred. 
gravitate towards the lower boundary 110, presumably because beliefs are more pessimistic. This "history dependence" is not picked up by equilibrium models such as the one implied by maximizing stochastic potential. Nevertheless, the predictions that follow from maximizing stochastic potential are remarkably accurate when we aggregate the sessions in the same treatment. The averages for the two treatments end up at about 126(14) for the high-cost treatment and at 159(11) for the low-cost treatment, which is only slightly more extreme than the stochastic potential predictions of 126(12) and 154(12) based on the estimated error parameter. To summarize: The average effort trajectories spread symmetrically and converge to levels near those implied by maximizing the stochastic potential function.

\section{Minimum and Median-Effort Games with Three Players}

Some researchers have suggested that two is the critical number of players for efficient coordination. For instance, in the minimum-effort coordination experiments of Knez and Camerer (1994), coordination gets steadily worse with larger groups and the biggest decrease in efficiency occurs when going from two to three players. Their explanation is that with more than two players, beliefs about others' behavior become ambiguous: while two players only have to worry about each others' beliefs about one another, the introduction of additional players forces everyone to think about beliefs one opponent has about another.

From the point of view of maximum (stochastic) potential, however, there is nothing special about a group size of two: depending on the value of $n c$, average effort levels may be either low or high with two players (see Figure 2), and the same is true for three (or more) players. To test this prediction, we ran two new minimum-effort coordination sessions, now with cohorts of twelve subjects being randomly matched in groups of three. The effort-cost was $1 / 2$ in the high-cost treatment and 1/10 and in the low-cost treatment. ${ }^{22}$ In order to get an ex ante prediction for the average effort levels in the final periods, we shall use $\mu=7.4$, which was estimated from the two-person experiment. The population density that maximizes the stochastic

\footnotetext{
22 We would liked to have set $c=1 / 6$ (instead of $c=1 / 10$ ) in the low-cost treatment to preserve symmetry around $n c=1$, but we felt that this would complicate payoff calculations too much and slow down the experiments, which were done by hand. The low value of $1 / 10$, however, has the disadvantage that it can cause decisions to "lock" onto the upper boundary.
} 
potential is characterized by the three-person generalization of equation (4):

$$
\mu f^{\prime}(e)=f(e)\left((1-F(e))^{2}-c\right) .
$$

Equation (5) can be derived as follows. Recall that, in general, the condition for stochastic potential maximization is given by the logit-equilibrium condition: $\mu f^{\prime}(e)=\pi^{\mathrm{e}}(e) f(e)$. An increase in effort raises costs at a rate $c$ and results in a higher minimum effort only if the others' efforts are higher, which occurs with probability $(1-F)^{2}$. Hence marginal payoffs are: $\pi^{\mathrm{e}^{\prime}}=(1$ $F)^{2}-c$, which together with the logit condition yields (5). Using the estimated value of 7.4 for the error parameter, equation (5) can be solved numerically and the resulting predictions for the average effort levels are: 154 for $c=1 / 10$ and 129 for $c=1 / 2$, and the standard deviation of the average is 8 in each case. The period-by-period average effort levels for both treatments are shown in Figure 4.

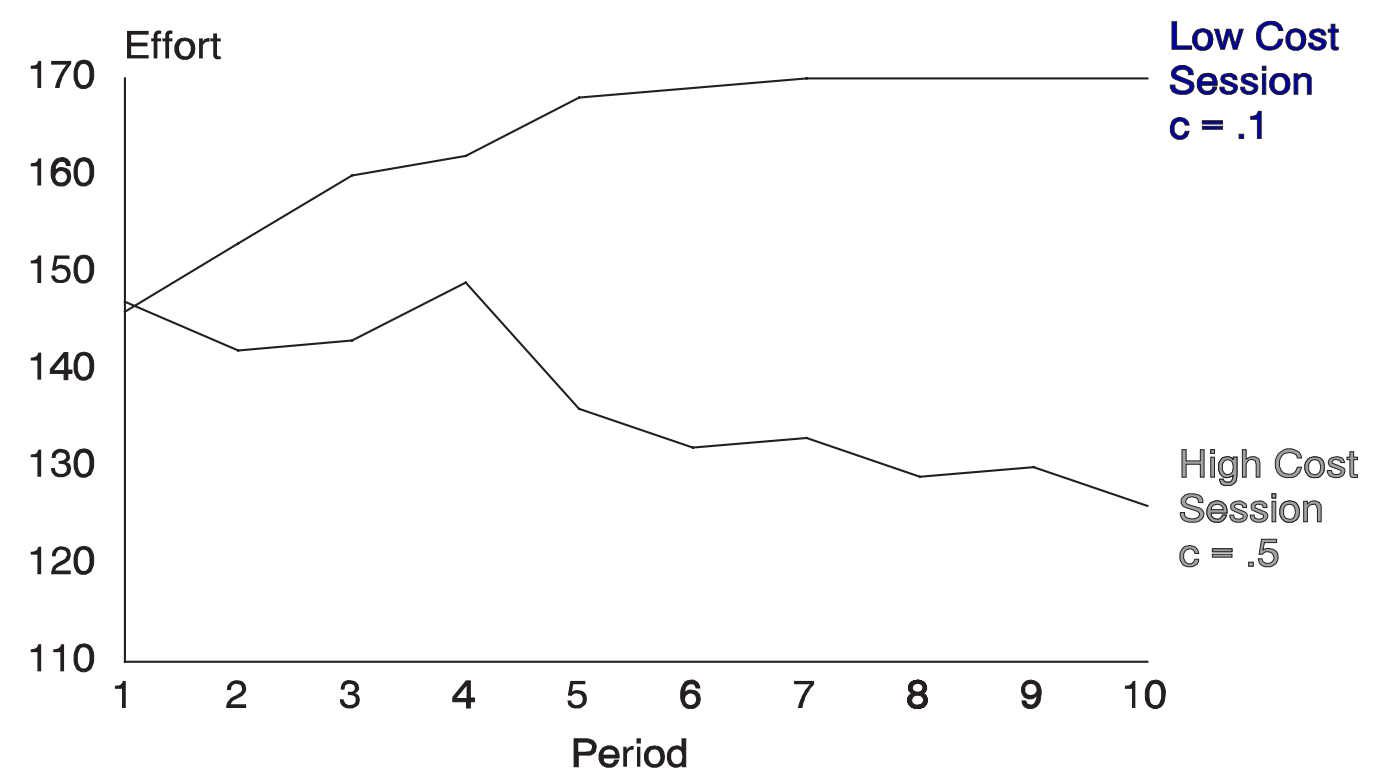

Figure 4. A Three-Person Minimum-Effort Coordination Game: Average Effort Decisions Key: Averages by period for $c=1 / 10$ (top) and $c=1 / 2$ (bottom).

Both sessions start out at the same level, which falls in the same range (between 140 and 
150) as in the sessions with random pairings. As predicted, however, average effort levels in the high-cost session fall while average effort levels rise in the low-cost session. The average efforts for the high-cost session end up quite close to the logit predictions. ${ }^{23}$

\section{A Median-Effort Coordination Game}

Another characteristic of coordination experiments done to date is that when payoffs are determined by the median effort, the dynamics exhibit strong history-dependence: i.e. final outcomes are largely determined by initial play (Van Huyck, Battalio, and Beil, 1991). In all of the twelve sessions that they report, the median choice remained the same in each period and the final outcome was completely determined by first-period play. In addition, subjects' behavior showed little variation over time, in contrast with the adjustment patterns in minimum-effort games (see also Crawford, 1995).

The payoff structure in Van Huyck, Battalio, and Beil (1991) differs from (1) in two ways. The minimum of all efforts is replaced by the median, and, more importantly, a cost is added that is quadratic in the distance between a player's effort and the median of all effort choices. The latter change may have an effect on behavior and could be part of the reason why the data show such strong history dependence. We will consider a three-person median-effort coordination game with a payoff structure that is more closely related to (1). In particular, all three players receive the median, or middle, effort choice minus the cost of their own effort: $\pi_{\mathrm{i}}\left(e_{1}, e_{2}, e_{3}\right)=$ median $\left\{e_{1}, e_{2}, e_{3}\right\}-c e_{\mathrm{i}}$, with $c$ the effort-cost parameter. This median-effort game has a continuum of asymmetric Pareto-ranked Nash equilibria in which two players choose a common effort level, $e$, and the third player chooses the lowest possible effort $\underline{e}$. This asymmetric outcome is unlikely to be observed when players are randomly matched and drawn from the same pool, and it seems more sensible to characterize the entire population of players by a common distribution function $F$, with corresponding density $f$. The condition implied by maximum stochastic potential is: $\mu f^{\prime}(e)=\pi^{\mathfrak{e}^{\mathrm{e}}}(e) f(e)$, and the marginal payoff function can be derived in the same manner as above. An increase in effort raises costs at a rate $c$ and affects

23 The low-cost session, however, provides an example of "lock-in dynamics:" there is no more residual noise and behavior gets stuck at the upper boundary after period 7. 
the median only if one of the other players is choosing a higher effort level and the other a lower effort level, which happens with probability $2 F(1-F)$. Hence, the condition for maximum stochastic potential becomes:

$$
\mu f^{\prime}(e)=f(e)(2 F(e)(1-F(e))-c) .
$$

We conducted four sessions with this particular game form, with effort-cost parameters of $c=0.1, c=0.4$, and $c=0.6$ respectively. The predictions for the final-period average effort levels that follow from (10) (again with $\mu=7.4$ ) are: 150 for $c=0.1,140$ for $c=0.4$, and 130 for $c=0.6$ with a standard deviation of 8 in each case. The observed average efforts in the last three periods for these sessions were $157(c=0.1), 136$ and $138(c=0.4)$, and $113(c=0.6)$ respectively. Notice that three of the four averages are within one standard deviation of the relevant theoretical prediction.

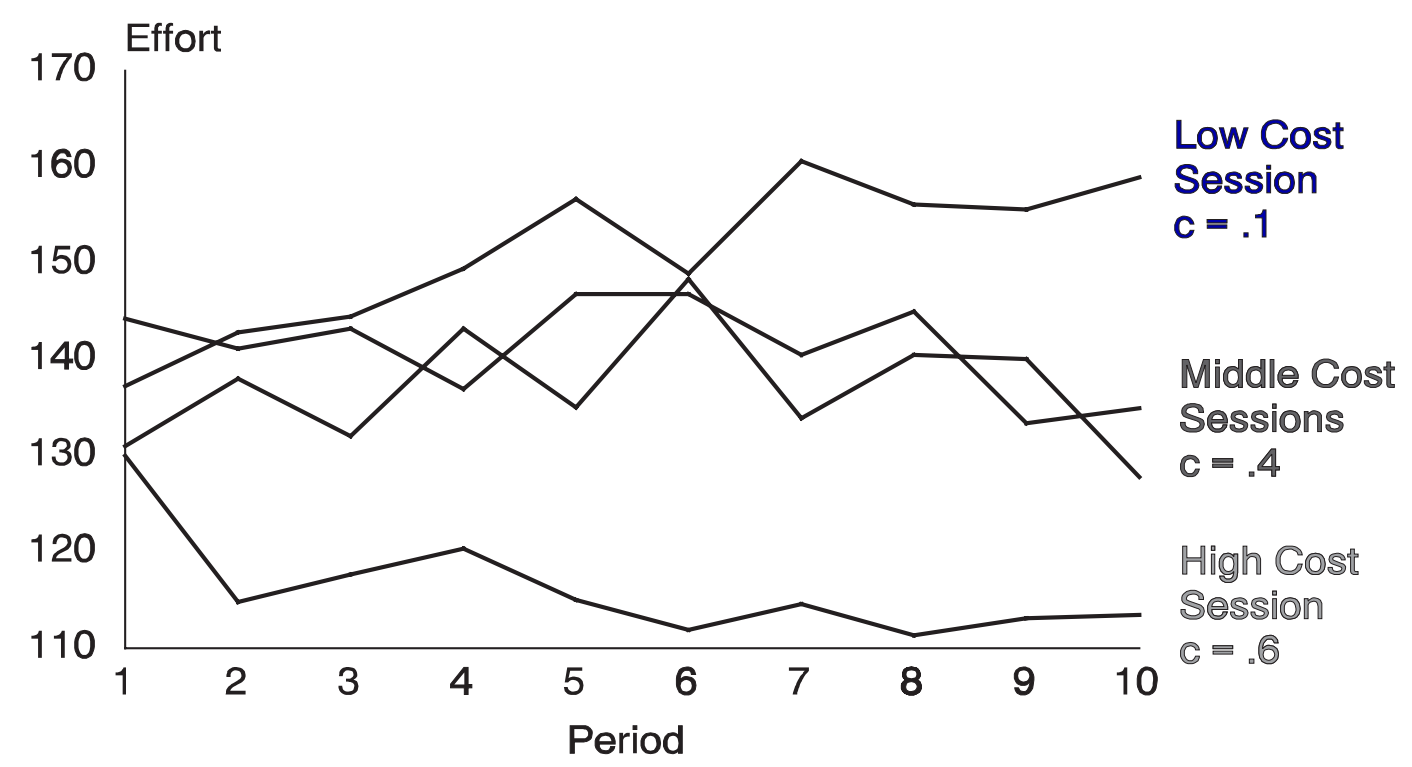

Figure 5: A Median-Effort Coordination Game: Average Effort Decisions Key: Averages by period for $c=0.1$ (top), $c=0.4$ (middle), and $c=0.6$ (bottom).

Figure 5 shows the period-by-period averages for each treatment. Average efforts start 
at roughly the same level, but rise in the session with the lowest effort cost and fall in the one with the highest cost. The sessions with the intermediate effort cost have relatively flat trajectories, which is consistent with history dependence, but the final level is also predicted by maximizing stochastic potential. For later periods, the null hypothesis of no treatment effect can be rejected at the 10 percent level of significance using a non-parametric test. ${ }^{24}$ To summarize: behavior in three-person minimum and median-effort coordination games is sensitive to changes in the effort cost that do not affect the set of Nash equilibria. In most sessions, average effort levels in final periods are close to those implied by maximization of stochastic potential.

\section{CONCLUSION}

Coordination games are of interest to both macroeconomists and microeconomists because the presence of multiple, Pareto-ranked Nash equilibria raises the possibility of failure to coordinate on a "good" outcome. One direction of research has been to devise and study mechanisms that facilitate profitable coordination. In addition, theorists have studied coordination games extensively because the presence of multiple equilibria provides a useful platform for the analysis of strategic behavior. This paper reports a new set of experimental data generated by changes in the economic variables, i.e. effort cost and group size, which should affect the likelihood of successful coordination.

In the continuous minimum-effort game, a unilateral increase in effort above some common level will reduce one's payoff by $c$ per unit effort, whereas a unilateral one-unit decrease in effort will reduce payoff by $1-c$, since the minimum effort is reduced by 1 . Thus any common effort level is a Nash equilibrium, but intuition suggests that the average effort levels should depend on the relative losses from over-shooting or under-shooting the other's effort, i.e. on whether $c$ is greater than or less than $1 / 2$. The widely cited notion of "risk dominance" uses these "deviation losses" to predict which outcome will occur in a two-decision game. One way to generalize risk dominance to economic situations with a continuum of decisions is to consider the equilibrium that maximizes a "potential function." In the two-person

24 There are 24 possible ways that the effort averages could have been ranked, and of these only two rankings are as extreme as the one observed. The probability of this outcome under the null is, therefore, $2 / 24=0.09$. 
coordination game, this procedure selects the equilibrium with the highest possible effort when $c<1 / 2$ and with the lowest possible effort when $c>1 / 2$. This paper presents the results of a laboratory experiment using effort cost parameters of $1 / 4$ and $3 / 4$. The effort-cost treatment separates the data nicely, with symmetric increases for low effort costs and decreases for high effort costs, as shown by the dark lines in Figure 2 that track the average efforts by treatment for each period.

The data averages do not converge to the upper and lower boundaries, as implied by the maximization of potential, and the residual noise in the data suggests the incorporation of stochastic elements, reflecting noisy response to asymmetries in deviation losses. We use a "stochastic potential" function which includes an entropy term that is weighted by an estimated error parameter. The final-period averages are close to the levels that maximize stochastic potential. Follow-up experiments show that this approach is also useful in organizing the data from different contexts, e.g. three-person minimum and median effort-coordination games. Overall, this combination of theory and experiment provides a coherent picture of behavioral responses to key economic incentives and can be useful in designing mechanisms that facilitate coordination. 


\section{Appendix A: Instructions (for the $\mathrm{c}=\mathbf{0 . 2 5}$ treatment)}

\section{Introduction}

You are going to take part in an experimental study of decision making. The funding for this study has been provided by several foundations. The instructions are simple, and by following them carefully, you may earn a considerable amount of money. At this time, you will be given $\$ 6$ for coming on time. All the money that you earn subsequently will be yours to keep, and your earnings will be paid to you in cash today at the end of this experiment. We will start by reading the instructions, and then you will have the opportunity to ask questions about the procedures described.

\section{Earnings}

The experiment consists of a number of periods. In each period, you will be randomly matched with another participant in the room. The decisions that you and the other participant make will determine the amount earned by each of you. At the beginning of each period, you will choose a number or "effort level" between 110 and 170. Effort choices will be made by writing the effort level on a decision sheet that is attached to these instructions. Your effort choice may be any amount between and including 110 and 170. That is, we allow fractions. The person who you are matched with will also choose an effort level between and including 110 and 170. Your earnings are determined as follows: you will receive a penny amount that equals the minimum of the two effort levels chosen, minus the cost of your effort, which is .25 times your own effort choice. So if the effort levels are equal, both players receive their effort level minus .25 times their effort level (in pennies). If the effort levels are not equal, both players get the lower of the two effort levels, minus .25 times their effort level.

Example: $\quad$ Suppose that your effort is $\mathrm{X}$ and the other's effort is $\mathrm{Y}$.

If $\mathrm{X}=\mathrm{Y}$, you get $\mathrm{X}-(.25) \mathrm{X}$, and the other gets $\mathrm{Y}-(.25) \mathrm{Y}$.

If $\mathrm{X}>\mathrm{Y}$, you get $\mathrm{Y}-(.25) \mathrm{X}$, and the other gets $\mathrm{Y}-(.25) \mathrm{Y}$.

If $\mathrm{X}<\mathrm{Y}$, you get $\mathrm{X}-(.25) \mathrm{X}$, and the other gets $\mathrm{X}-(.25) \mathrm{Y}$.

To reiterate, you each earn a number of pennies that equals the minimum effort, minus the cost of your own effort. In addition to the earnings determined in this manner, you will earn a fixed amount of 60 cents per round.

\section{Record of Results}

Now, each of you should examine the record sheet for part A. This sheet is the last one attached to these instructions. Your identification number is written in the top-right part of this sheet. Now, please look at the columns of your record sheet for part A. Going from left to right, you will see columns for the "period," "your effort," "other's effort," "minimum effort," "effort cost," and "your earnings." You begin by writing down your effort choice in the appropriate column. As mentioned above, this effort must be greater than or equal to 110 and less than or equal to 170, and the effort can be any amount in this range, (i.e. fractional effort levels are allowed). Use decimals to separate fractions. For example, wxy.z indicates wxy units of effort plus $\mathrm{z} / 10$ of a unit. 
After you make and record your decision for period one, we will collect all decision sheets. Then we will draw numbered ping pong balls to match each of you with another person. Here we have a container with ping pong balls, each ball has one of your identification numbers on it. We will draw the ping pong balls to determine who is matched with whom. After we have matched someone with you, we will write the other's effort decision, the minimum effort, the cost of your own effort, and your earnings in the relevant columns of your decision sheet and return it to you. Then, you make and record your decision for period two, we collect all decision sheets, draw ping pong balls to randomly match you with another person, and calculate your earnings as above. This same process is repeated a total number of ten times. Notice that the far right column in record sheet lists the additional 60 cents that you earn each round.

\section{Summary}

To begin, participants make and record their effort choices by writing the effort level in the appropriate column of the decision sheet. Then the decision sheets are collected and participants are randomly matched using draws of numbered ping pong balls. Once the matching is done, the other's effort, the minimum effort, the effort cost, and the earnings are written on each person's decision sheet. Then decision sheets are returned, and participants make and record their effort levels for the next period. The decisions determine each person's earnings in pennies as described above (you will receive an amount that equals the minimum of your effort and the other person's effort, minus the cost of your effort, which is (.25) times your effort level). Note that a new random matching is done in each period. After we finish all periods, we will read to you the instructions for a different experiment.

\section{Final Remarks}

At the end of today's session, we will pay to you, privately in cash, the amount that you have earned. We will add together your earnings from all parts of this exercise to determine your total earnings (earnings will be rounded off to the nearest penny amount). You have already received the $\$ 6$ participation payment. Therefore, if you earn an amount $\mathrm{X}$ during the exercise that follows, you will receive a total amount of $\$ 6.00+\mathrm{X}$. Your earnings are your own business, and you do not have to discuss them with anyone.

During the experiment, you are not permitted to speak or communicate with the other participants. If you have a question while the experiment is going on, please raise your hand and one of us will come answer it. At this time, do you have any questions about the instructions or procedures? If you have a question, please raise your hands and one of us will come to your seat to answer it. 
Identification Number:

Choose an effort level that is greater than or equal to 110 and less than or equal to 170 , using decimals to indicate fractions; e.g. wxy.z. Please only make a decision for period 1 at this time, which is recorded in the top row.

\begin{tabular}{|c|c|c|c|c|c|c|}
\hline \hline period & $\begin{array}{c}\text { your } \\
\text { effort }\end{array}$ & $\begin{array}{c}\text { other's } \\
\text { effort }\end{array}$ & $\begin{array}{c}\text { minimum } \\
\text { effort }\end{array}$ & $\begin{array}{c}\text { effort cost } \\
(.25) * \text { your effort }\end{array}$ & $\begin{array}{c}\text { your } \\
\text { earnings } \\
\text { in cents }\end{array}$ & $\begin{array}{c}\text { additional } \\
\text { payment }\end{array}$ \\
\hline 1 & & & & & & +60 \\
\hline 2 & & & & & & +60 \\
\hline
\end{tabular}




\section{Appendix B: Data for the Minimum-Effort Game}

Session 1: Effort Decisions (Other's Decision) for Effort Cost $c=0.25$

\begin{tabular}{|c|c|c|c|c|c|c|c|c|c|c|}
\hline & subject 1 & subject 2 & ubject 3 & ubject 4 & & t 6 & ect 7 & subje & subject 9 & subje \\
\hline period 1 & $\begin{array}{c}135 \\
(140)\end{array}$ & $\begin{array}{c}140 \\
(155)\end{array}$ & $\begin{array}{c}120 \\
(110)\end{array}$ & $\begin{array}{c}110 \\
(120)\end{array}$ & $\begin{array}{c}140 \\
(135)\end{array}$ & $\begin{array}{c}135.25 \\
(148)\end{array}$ & $\begin{array}{c}120 \\
(170)\end{array}$ & $\begin{array}{c}170 \\
(120)\end{array}$ & $\begin{array}{c}155 \\
(140)\end{array}$ & $\begin{array}{c}148 \\
(135.25)\end{array}$ \\
\hline period 2 & $\begin{array}{l}143.5 \\
(170)\end{array}$ & $\begin{array}{c}170 \\
(143.5)\end{array}$ & $\begin{array}{l}115.9 \\
(170)\end{array}$ & $\begin{array}{c}130 \\
(140)\end{array}$ & $\begin{array}{c}140 \\
(130)\end{array}$ & $\begin{array}{c}153.52 \\
(130)\end{array}$ & $\begin{array}{c}170 \\
(115.9)\end{array}$ & $\begin{array}{c}130 \\
(153.52)\end{array}$ & $\begin{array}{c}150 \\
(128)\end{array}$ & $\begin{array}{c}128 \\
(150)\end{array}$ \\
\hline period 3 & $\begin{array}{c}155 \\
(111.9)\end{array}$ & $\begin{array}{c}160 \\
(140)\end{array}$ & $\begin{array}{l}111.9 \\
(155)\end{array}$ & $\begin{array}{c}135 \\
(170)\end{array}$ & $\begin{array}{c}140 \\
(140)\end{array}$ & $\begin{array}{c}140 \\
(138.9)\end{array}$ & $\begin{array}{c}170 \\
(135)\end{array}$ & $\begin{array}{c}140 \\
(140)\end{array}$ & $\begin{array}{c}140 \\
(160)\end{array}$ & $\begin{array}{l}138.9 \\
(140)\end{array}$ \\
\hline period 4 & $\begin{array}{c}140 \\
(140)\end{array}$ & $\begin{array}{c}160 \\
(150)\end{array}$ & $\begin{array}{l}135.5 \\
(145)\end{array}$ & $\begin{array}{c}145 \\
(135.5)\end{array}$ & $\begin{array}{c}140 \\
(140)\end{array}$ & $\begin{array}{c}142.85 \\
(170)\end{array}$ & $\begin{array}{c}170 \\
(142.85)\end{array}$ & $\begin{array}{c}150 \\
(139)\end{array}$ & $\begin{array}{c}150 \\
(160)\end{array}$ & $\begin{array}{c}139 \\
(150)\end{array}$ \\
\hline period 5 & $\begin{array}{c}150 \\
(150)\end{array}$ & $\begin{array}{c}150 \\
(150)\end{array}$ & $\begin{array}{l}140.5 \\
(140)\end{array}$ & $\begin{array}{c}135.5 \\
(145.28)\end{array}$ & $\begin{array}{c}140 \\
(140.5)\end{array}$ & $\begin{array}{l}145.28 \\
(135.5)\end{array}$ & $\begin{array}{c}160 \\
(139.9)\end{array}$ & $\begin{array}{l}139.9 \\
(160)\end{array}$ & $\begin{array}{c}155 \\
(138.9)\end{array}$ & $\begin{array}{l}138.9 \\
(155)\end{array}$ \\
\hline period 6 & $\begin{array}{c}155.5 \\
(149.9)\end{array}$ & $\begin{array}{c}150 \\
(160)\end{array}$ & $\begin{array}{l}160.5 \\
(140)\end{array}$ & $\begin{array}{c}140 \\
(155)\end{array}$ & $\begin{array}{c}140 \\
(148.52)\end{array}$ & $\begin{array}{c}148.52 \\
(140)\end{array}$ & $\begin{array}{c}140 \\
(160.5)\end{array}$ & $\begin{array}{c}160 \\
(150)\end{array}$ & $\begin{array}{c}155 \\
(140)\end{array}$ & $\begin{array}{c}149.9 \\
(155.5)\end{array}$ \\
\hline period 7 & $\begin{array}{c}145 \\
(140)\end{array}$ & $\begin{array}{c}160 \\
(160)\end{array}$ & $\begin{array}{l}140.5 \\
(170)\end{array}$ & $\begin{array}{c}140 \\
(153)\end{array}$ & $\begin{array}{c}140 \\
(145)\end{array}$ & $\begin{array}{c}145.98 \\
(150)\end{array}$ & $\begin{array}{c}170 \\
(140.5)\end{array}$ & $\begin{array}{c}150 \\
(145.98)\end{array}$ & $\begin{array}{c}153 \\
(140)\end{array}$ & $\begin{array}{c}159 \\
(160)\end{array}$ \\
\hline period 8 & $\begin{array}{c}140 \\
(146.54)\end{array}$ & $\begin{array}{c}160 \\
(140.5)\end{array}$ & $\begin{array}{l}140.5 \\
(160)\end{array}$ & $\begin{array}{c}145 \\
(140)\end{array}$ & $\begin{array}{c}140 \\
(145)\end{array}$ & $\begin{array}{c}146.54 \\
(140)\end{array}$ & $\begin{array}{c}160 \\
(145)\end{array}$ & $\begin{array}{c}145 \\
(160)\end{array}$ & $\begin{array}{c}150 \\
(169)\end{array}$ & $\begin{array}{c}169 \\
(150)\end{array}$ \\
\hline period 9 & $\begin{array}{c}150 \\
(164)\end{array}$ & $\begin{array}{c}160 \\
(140)\end{array}$ & $\begin{array}{c}140 \\
(160)\end{array}$ & $\begin{array}{c}143 \\
(140)\end{array}$ & $\begin{array}{c}140 \\
(143)\end{array}$ & $\begin{array}{c}146.02 \\
(160)\end{array}$ & $\begin{array}{c}150 \\
(155)\end{array}$ & $\begin{array}{c}160 \\
(146.02)\end{array}$ & $\begin{array}{c}155 \\
(150)\end{array}$ & $\begin{array}{c}164 \\
(150)\end{array}$ \\
\hline period 10 & $\begin{array}{c}170 \\
(170)\end{array}$ & $\begin{array}{c}160 \\
(155)\end{array}$ & $\begin{array}{l}141.1 \\
(140)\end{array}$ & $\begin{array}{c}143 \\
(160)\end{array}$ & $\begin{array}{c}140 \\
(141.1)\end{array}$ & $\begin{array}{c}146.22 \\
(149)\end{array}$ & $\begin{array}{c}170 \\
(170)\end{array}$ & $\begin{array}{c}160 \\
(143)\end{array}$ & $\begin{array}{c}155 \\
(160)\end{array}$ & $\begin{array}{c}149 \\
(146.22)\end{array}$ \\
\hline
\end{tabular}

Session 2: Effort Decision (Other's Decision) for Effort Cost $c=0.75$

\begin{tabular}{|c|c|c|c|c|c|c|c|c|c|c|}
\hline & ubject 1 & abject 2 & bject 3 & ubject 4 & subject 5 & subject 6 & subject 7 & subject 8 & subject 9 & subject 10 \\
\hline period 1 & $\begin{array}{c}150 \\
(139.8)\end{array}$ & $\begin{array}{c}125 \\
(148)\end{array}$ & $\begin{array}{c}150 \\
(170)\end{array}$ & $\begin{array}{c}125 \\
(160)\end{array}$ & $\begin{array}{l}139.8 \\
(150)\end{array}$ & $\begin{array}{c}148 \\
(125)\end{array}$ & $\begin{array}{c}170 \\
(150)\end{array}$ & $\begin{array}{l}135.2 \\
(110)\end{array}$ & $\begin{array}{c}160 \\
(125)\end{array}$ & $\begin{array}{c}110 \\
(135.2)\end{array}$ \\
\hline period 2 & $\begin{array}{l}136.1 \\
(170)\end{array}$ & $\begin{array}{c}170 \\
(130)\end{array}$ & $\begin{array}{c}150 \\
(150)\end{array}$ & $\begin{array}{c}135 \\
(129.6)\end{array}$ & $\begin{array}{l}129.6 \\
(135)\end{array}$ & $\begin{array}{c}169 \\
(140.5)\end{array}$ & $\begin{array}{c}170 \\
(136.1)\end{array}$ & $\begin{array}{l}140.5 \\
(169)\end{array}$ & $\begin{array}{c}130 \\
(170)\end{array}$ & $\begin{array}{c}120 \\
(120)\end{array}$ \\
\hline period 3 & $\begin{array}{l}134.7 \\
(170)\end{array}$ & $\begin{array}{c}170 \\
(110)\end{array}$ & $\begin{array}{c}170 \\
(134.7)\end{array}$ & $\begin{array}{c}125 \\
(140)\end{array}$ & $\begin{array}{c}155 \\
(150)\end{array}$ & $\begin{array}{c}125 \\
(125)\end{array}$ & $\begin{array}{c}110 \\
(170)\end{array}$ & $\begin{array}{c}150 \\
(155)\end{array}$ & $\begin{array}{c}140 \\
(125)\end{array}$ & $\begin{array}{c}125 \\
(125)\end{array}$ \\
\hline period 4 & $\begin{array}{l}138.1 \\
(145)\end{array}$ & $\begin{array}{c}110 \\
(135)\end{array}$ & $\begin{array}{c}145 \\
(138.1)\end{array}$ & $\begin{array}{c}140 \\
(140)\end{array}$ & $\begin{array}{c}149 \\
(125)\end{array}$ & $\begin{array}{c}125 \\
(149)\end{array}$ & $\begin{array}{c}170 \\
(145.5)\end{array}$ & $\begin{array}{l}145.5 \\
(170)\end{array}$ & $\begin{array}{c}140 \\
(140)\end{array}$ & $\begin{array}{c}135 \\
(110)\end{array}$ \\
\hline period 5 & $\begin{array}{l}141.2 \\
(110)\end{array}$ & $\begin{array}{c}110 \\
(135)\end{array}$ & $\begin{array}{c}160 \\
(140)\end{array}$ & $\begin{array}{c}140 \\
(170)\end{array}$ & $\begin{array}{c}160 \\
(129.6)\end{array}$ & $\begin{array}{c}135 \\
(110)\end{array}$ & $\begin{array}{c}170 \\
(140)\end{array}$ & $\begin{array}{l}129.6 \\
(160)\end{array}$ & $\begin{array}{c}140 \\
(160)\end{array}$ & $\begin{array}{c}110 \\
(141.2)\end{array}$ \\
\hline period 6 & $\begin{array}{c}135 \\
(145)\end{array}$ & $\begin{array}{c}110 \\
(150)\end{array}$ & $\begin{array}{c}150 \\
(110)\end{array}$ & $\begin{array}{c}150 \\
(140)\end{array}$ & $\begin{array}{l}130.8 \\
(115)\end{array}$ & $\begin{array}{c}125 \\
(125)\end{array}$ & $\begin{array}{c}140 \\
(150)\end{array}$ & $\begin{array}{l}155.7 \\
(125)\end{array}$ & $\begin{array}{c}145 \\
(145)\end{array}$ & $\begin{array}{c}115 \\
(130.8)\end{array}$ \\
\hline period 7 & $\begin{array}{c}139 \\
(125)\end{array}$ & $\begin{array}{c}110 \\
(140)\end{array}$ & $\begin{array}{c}140 \\
(140)\end{array}$ & $\begin{array}{c}140 \\
(140)\end{array}$ & $\begin{array}{c}116 \\
(145)\end{array}$ & $\begin{array}{c}125 \\
(125)\end{array}$ & $\begin{array}{c}140 \\
(110)\end{array}$ & $\begin{array}{c}125 \\
(125)\end{array}$ & $\begin{array}{c}145 \\
(116)\end{array}$ & $\begin{array}{c}125 \\
(139)\end{array}$ \\
\hline period 8 & $\begin{array}{c}137 \\
(125)\end{array}$ & $\begin{array}{c}110 \\
(150)\end{array}$ & $\begin{array}{c}150 \\
(110)\end{array}$ & $\begin{array}{c}140 \\
(130)\end{array}$ & $\begin{array}{c}120 \\
(140)\end{array}$ & $\begin{array}{c}125 \\
(137)\end{array}$ & $\begin{array}{c}140 \\
(120)\end{array}$ & $\begin{array}{c}130 \\
(140)\end{array}$ & $\begin{array}{c}140 \\
(125)\end{array}$ & $\begin{array}{c}125 \\
(140)\end{array}$ \\
\hline period 9 & $\begin{array}{c}131 \\
(140)\end{array}$ & $\begin{array}{c}110 \\
(135.4)\end{array}$ & $\begin{array}{c}140 \\
(131)\end{array}$ & $\begin{array}{c}140 \\
(140)\end{array}$ & $\begin{array}{c}120 \\
(125)\end{array}$ & $\begin{array}{c}135 \\
(140)\end{array}$ & $\begin{array}{c}140 \\
(140)\end{array}$ & $\begin{array}{l}135.4 \\
(110)\end{array}$ & $\begin{array}{c}140 \\
(135)\end{array}$ & $\begin{array}{c}125 \\
(120)\end{array}$ \\
\hline period 10 & $\begin{array}{c}135 \\
(135)\end{array}$ & $\begin{array}{c}110 \\
(121)\end{array}$ & $\begin{array}{c}135 \\
(135)\end{array}$ & $\begin{array}{c}140 \\
(120)\end{array}$ & $\begin{array}{c}121 \\
(110)\end{array}$ & $\begin{array}{c}135 \\
(140)\end{array}$ & $\begin{array}{c}140 \\
(125)\end{array}$ & $\begin{array}{c}125 \\
(140)\end{array}$ & $\begin{array}{c}140 \\
(135)\end{array}$ & $\begin{array}{c}120 \\
(140)\end{array}$ \\
\hline
\end{tabular}


Session 3: Effort Decision (Other's Decision) for Effort Cost $c=0.25$

\begin{tabular}{ccccccccccc}
\hline \hline & subject 1 & subject 2 & subject 3 & subject 4 & subject 5 & subject 6 & subject 7 & subject 8 & subject 9 & subject 10 \\
\hline period 1 & 150 & 170 & 133.3 & 170 & 160.8 & 140 & 170 & 120 & 110 & 170 \\
& $(170)$ & $(133.3)$ & $(170)$ & $(150)$ & $(140)$ & $(160.8)$ & $(110)$ & $(170)$ & $(170)$ & $(120)$ \\
period 2 & 165 & 160 & 170 & 150 & 159.7 & 140 & 170 & 140 & 110 & 170 \\
& $(150)$ & $(110)$ & $(170)$ & $(165)$ & $(140)$ & $(159.7)$ & $(140)$ & $(170)$ & $(160)$ & $(170)$ \\
period 3 & 160 & 160 & 170 & 150 & 140 & 140 & 170 & 160 & 150 & 170 \\
& $(160)$ & $(140)$ & $(140)$ & $(170)$ & $(170)$ & $(160)$ & $(150)$ & $(160)$ & $(170)$ & $(150)$ \\
period 4 & 170 & 150 & 170 & 160 & 170 & 140 & 170 & 160 & 155 & 170 \\
& $(150)$ & $(170)$ & $(140)$ & $(160)$ & $(170)$ & $(170)$ & $(170)$ & $(160)$ & $(170)$ & $(155)$ \\
period 5 & 160 & 145 & 170 & 160 & 170 & 150 & 170 & 160 & 160 & 170 \\
& $(170)$ & $(160)$ & $(160)$ & $(145)$ & $(160)$ & $(170)$ & $(160)$ & $(170)$ & $(170)$ & $(150)$ \\
period 6 & 160 & 160 & 170 & 150 & 170 & 150 & 170 & 160 & 170 & 170 \\
& $(160)$ & $(170)$ & $(160)$ & $(150)$ & $(170)$ & $(150)$ & $(170)$ & $(160)$ & $(170)$ & $(170)$ \\
period 7 & 160 & 160 & 170 & 150 & 170 & 150 & 170 & 160 & 170 & 170 \\
& $(170)$ & $(170)$ & $(150)$ & $(160)$ & $(160)$ & $(170)$ & $(170)$ & $(150)$ & $(160)$ & $(170)$ \\
period 8 & 170 & 160 & 170 & 155 & 160 & 155 & 170 & 160 & 170 & 170 \\
& $(170)$ & $(170)$ & $(155)$ & $(170)$ & $(155)$ & $(160)$ & $(160)$ & $(170)$ & $(170)$ & $(160)$ \\
period 9 & 170 & 169.9 & 170 & 160 & 170 & 160 & 170 & 160 & 170 & 170 \\
& $(170)$ & $(170)$ & $(160)$ & $(170)$ & $(170)$ & $(170)$ & $(160)$ & $(170)$ & $(169.9)$ & $(160)$ \\
period 10 & 170 & 170 & 170 & 165 & 170 & 160 & 170 & 160 & 170 & 170 \\
& $(160)$ & $(170)$ & $(170)$ & $(160)$ & $(170)$ & $(170)$ & $(170)$ & $(165)$ & $(170)$ & $(170)$ \\
\hline
\end{tabular}

Session 4: Effort Decision (Other's Decision) for Effort Cost $c=0.75$

\begin{tabular}{ccccccccccc}
\hline \hline & subject 1 & subject 2 & subject 3 & subject 4 & subject 5 & subject 6 & subject 7 & subject 8 & subject 9 & subject 10 \\
\hline period 1 & 122 & 160 & 170 & 130.5 & 134.9 & 150 & 170 & 150 & 110 & 170 \\
& $(130.5)$ & $(150)$ & $(110)$ & $(122)$ & $(170)$ & $(160)$ & $(150)$ & $(170)$ & $(170)$ & $(134.9)$ \\
period 2 & 169 & 130 & 110 & 170 & 140 & 150 & 110 & 150 & 110 & 140 \\
& $(110)$ & $(170)$ & $(169)$ & $(130)$ & $(110)$ & $(140)$ & $(150)$ & $(110)$ & $(140)$ & $(150)$ \\
period 3 & 131 & 140 & 120 & 140.2 & 135 & 145 & 110 & 140 & 110 & 140 \\
& $(195)$ & $(140)$ & $(140.2)$ & $(120)$ & $(110)$ & $(131)$ & $(135)$ & $(140)$ & $(140)$ & $(110)$ \\
period 4 & 127 & 135 & 130 & 125 & 135 & 120 & 110 & 130 & 110 & 110 \\
& $(130)$ & $(110)$ & $(135)$ & $(110)$ & $(130)$ & $(110)$ & $(135)$ & $(127)$ & $(120)$ & $(125)$ \\
period 5 & 134 & 110 & 130 & 110 & 130 & 110 & 110 & 130 & 110 & 110 \\
& $(110)$ & $(130)$ & $(110)$ & $(130)$ & $(110)$ & $(134)$ & $(110)$ & $(110)$ & $(110)$ & $(130)$ \\
period 6 & 152 & 125 & 120 & 120 & 110 & 128 & 110 & 120 & 140 & 110 \\
& $(110)$ & $(120)$ & $(128)$ & $(110)$ & $(152)$ & $(120)$ & $(110)$ & $(125)$ & $(110)$ & $(120)$ \\
period 7 & 112 & 120 & 130 & 110 & 130 & 124 & 110 & 120 & 110 & 110 \\
& $(120)$ & $(112)$ & $(130)$ & $(110)$ & $(130)$ & $(110)$ & $(120)$ & $(110)$ & $(110)$ & $(124)$ \\
period 8 & 110 & 115 & 120 & 110 & 130 & 110 & 110 & 120 & 110 & 110 \\
& $(115)$ & $(110)$ & $(110)$ & $(120)$ & $(110)$ & $(130)$ & $(110)$ & $(110)$ & $(110)$ & $(120)$ \\
period 9 & 113 & 110 & 120 & 110 & 110 & 114 & 110 & 110 & 110 & 110 \\
& $(110)$ & $(110)$ & $(110)$ & $(110)$ & $(110)$ & $(110)$ & $(110)$ & $(113)$ & $(120)$ & $(114)$ \\
period 10 & 111 & 110 & 110 & 110 & 110 & 110 & 110 & 110 & 110 & 110 \\
& $(110)$ & $(110)$ & $(111)$ & $(110)$ & $(110)$ & $(110)$ & $(110)$ & $(110)$ & $(110)$ & $(110)$ \\
\hline
\end{tabular}


Session 5: Effort Decision (Other's Decision) for Effort Cost $c=0.25$

\begin{tabular}{ccccccccccc}
\hline \hline & subject 1 & subject 2 & subject 3 & subject 4 & subject 5 & subject 6 & subject 7 & subject 8 & subject 9 & subject 10 \\
\hline period 1 & 157.2 & 110 & 140 & 170 & 160 & 130 & 150 & 150 & 140 & 130 \\
& $(140)$ & $(140)$ & $(110)$ & $(130)$ & $(150)$ & $(170)$ & $(160)$ & $(130)$ & $(157.2)$ & $(150)$ \\
period 2 & 143 & 140 & 135 & 110 & 160 & 170 & 150 & 140 & 160 & 140 \\
& $(135)$ & $(160)$ & $(143)$ & $(140)$ & $(150)$ & $(140)$ & $(160)$ & $(170)$ & $(140)$ & $(110)$ \\
period 3 & 161.3 & 145 & 150 & 140 & 150 & 150 & 150 & 160 & 160 & 110 \\
& $(140)$ & $(160)$ & $(150)$ & $(161.3)$ & $(150)$ & $(160)$ & $(110)$ & $(150)$ & $(145)$ & $(150)$ \\
period 4 & 159.9 & 160 & 130 & 150 & 170 & 170 & 170 & 170 & 170 & 130 \\
& $(130)$ & $(170)$ & $(159.9)$ & $(170)$ & $(160)$ & $(150)$ & $(170)$ & $(170)$ & $(130)$ & $(170)$ \\
period 5 & 132 & 170 & 150 & 150 & 170 & 170 & 140 & 170 & 160 & 130 \\
& $(150)$ & $(170)$ & $(132)$ & $(170)$ & $(140)$ & $(150)$ & $(170)$ & $(170)$ & $(130)$ & $(160)$ \\
period 6 & 141.8 & 170 & 146 & 170 & 160 & 160 & 150 & 170 & 160 & 130 \\
& $(146)$ & $(160)$ & $(141.8)$ & $(160)$ & $(170)$ & $(170)$ & $(130)$ & $(160)$ & $(170)$ & $(150)$ \\
period 7 & 142.6 & 170 & 142 & 170 & 160 & 160 & 150 & 170 & 160 & 140 \\
& $(170)$ & $(160)$ & $(160)$ & $(142.6)$ & $(142)$ & $(170)$ & $(140)$ & $(160)$ & $(170)$ & $(150)$ \\
period 8 & 140.4 & 165 & 144 & 160 & 170 & 170 & 150 & 170 & 170 & 135.5 \\
& $(135.5)$ & $(144)$ & $(165)$ & $(150)$ & $(170)$ & $(170)$ & $(160)$ & $(170)$ & $(170)$ & $(140.4)$ \\
period 9 & 145.1 & 170 & 151 & 160 & 170 & 170 & 150 & 170 & 170 & 140 \\
& $(170)$ & $(145.1)$ & $(160)$ & $(151)$ & $(170)$ & $(170)$ & $(170)$ & $(150)$ & $(140)$ & $(170)$ \\
period 10 & 146.5 & 170 & 147 & 170 & 170 & 170 & 150 & 170 & 170 & 140 \\
& $(150)$ & $(170)$ & $(170)$ & $(140)$ & $(147)$ & $(170)$ & $(146.5)$ & $(170)$ & $(170)$ & $(170)$ \\
\hline
\end{tabular}

Session 6: Effort Decision (Other's Decision) for Effort Cost $c=0.75$

\begin{tabular}{ccccccccccc}
\hline \hline & subject 1 & subject 2 & subject 3 & subject 4 & subject 5 & subject 6 & subject 7 & subject 8 & subject 9 & subject 10 \\
\hline period 1 & 110 & 170 & 140 & 159 & 130 & 110 & 150 & 120 & 140 & 170 \\
& $(170)$ & $(110)$ & $(150)$ & $(110)$ & $(170)$ & $(159)$ & $(140)$ & $(140)$ & $(120)$ & $(130)$ \\
period 2 & 170 & 170 & 140 & 120 & 140 & 110 & 150 & 120 & 140 & 170 \\
& $(110)$ & $(120)$ & $(150)$ & $(140)$ & $(170)$ & $(170)$ & $(140)$ & $(170)$ & $(120)$ & $(140)$ \\
period 3 & 135.15 & 170 & 170 & 111 & 170 & 110 & 150 & 170 & 140 & 170 \\
& $(170)$ & $(140)$ & $(110)$ & $(170)$ & $(111)$ & $(170)$ & $(170)$ & $(150)$ & $(170)$ & $(135.15)$ \\
period 4 & 141.67 & 140 & 140 & 130 & 130 & 145 & 170 & 150 & 140 & 170 \\
& $(140)$ & $(130)$ & $(170)$ & $(140)$ & $(145)$ & $(130)$ & $(140)$ & $(170)$ & $(141.67)$ & $(150)$ \\
period 5 & 137.19 & 140 & 140 & 110.1 & 130 & 130 & 160 & 150 & 140 & 170 \\
& $(130)$ & $(140)$ & $(140)$ & $(160)$ & $(170)$ & $(137.19)$ & $(110.1)$ & $(140)$ & $(150)$ & $(130)$ \\
period 6 & 158.75 & 140 & 140 & 150 & 140 & 130 & 160 & 130 & 140 & 129 \\
& $(129)$ & $(130)$ & $(140)$ & $(130)$ & $(160)$ & $(140)$ & $(140)$ & $(150)$ & $(140)$ & $(158.75)$ \\
period 7 & 116.85 & 135 & 140 & 110.1 & 145 & 130 & 160 & 140 & 140 & 129 \\
& $(135)$ & $(116.85)$ & $(145)$ & $(160)$ & $(140)$ & $(140)$ & $(110.1)$ & $(129)$ & $(130)$ & $(140)$ \\
period 8 & 140 & 128 & 140 & 130 & 130 & 130 & 160 & 120 & 140 & 129 \\
& $(146)$ & $(130)$ & $(130)$ & $(140)$ & $(129)$ & $(128)$ & $(120)$ & $(160)$ & $(140)$ & $(130)$ \\
period 9 & 140.10 & 130 & 140 & 130 & 120 & 130 & 160 & 130 & 140 & 129 \\
& $(130)$ & $(130)$ & $(160)$ & $(140)$ & $(140)$ & $(130)$ & $(140)$ & $(129)$ & $(120)$ & $(130)$ \\
period 10 & 125.87 & 130 & 140 & 129.9 & 130 & 130 & 160 & 125 & 160 & 129 \\
& $(160)$ & $(125)$ & $(130)$ & $(129)$ & $(160)$ & $(140)$ & $(125.89)$ & $(130)$ & $(130)$ & $(129.9)$ \\
\hline
\end{tabular}


Appendix C: Data for the Three Person Median-Effort Game

Session 1: Effort Decisions (Others' Decisions) for Effort Cost $c=0.10$

\begin{tabular}{cccccccccc}
\hline \hline & subject 1 & subject 2 & subject 3 & subject 4 & subject 5 & subject 6 & subject 7 & subject 8 & subject 9 \\
\hline period 1 & 170 & 110 & 150 & 140 & 130 & 170 & 120 & 135 & 110 \\
& $(130,140)$ & $(150,170)$ & $(110,170)$ & $(170,130)$ & $(170,140)$ & $(150,110)$ & $(110,135)$ & $(110,120)$ & $(120,135)$ \\
period 2 & 170 & 110 & 135 & 140 & 160 & 170 & 150 & 110 & 140 \\
& $(150,140)$ & $(110,170)$ & $(160,140)$ & $(150,170)$ & $(140,135)$ & $(110,110)$ & $(170,140)$ & $(110,170)$ & $(160,135)$ \\
period 3 & 170 & 110 & 170 & 110 & 110 & 150 & 170 & 160 & 150 \\
& $(110,170)$ & $(160,150)$ & $(110,170)$ & $(170,170)$ & $(150,170)$ & $(160,110)$ & $(110,150)$ & $(150,110)$ & $(110,170)$ \\
period 4 & 170 & 150 & 170 & 110 & 110 & 170 & 165 & 150 & 150 \\
& $(150,165)$ & $(110,170)$ & $(110,150)$ & $(150,170)$ & $(150,170)$ & $(110,150)$ & $(150,170)$ & $(110,170)$ & $(165,170)$ \\
period 5 & 170 & 150 & 170 & 110 & 170 & 170 & 150 & 150 & 170 \\
& $(150,170)$ & $(170,170)$ & $(110,150)$ & $(150,170)$ & $(170,150)$ & $(170,150)$ & $(110,170)$ & $(170,170)$ & $(150,170)$ \\
period 6 & 110 & 150 & 170 & 110 & 170 & 170 & 130 & 160 & 170 \\
& $(150,170)$ & $(110,170)$ & $(130,170)$ & $(160,170)$ & $(110,150)$ & $(130,170)$ & $(170,170)$ & $(110,170)$ & $(110,160)$ \\
period 7 & 170 & 170 & 170 & 165 & 170 & 170 & 110 & 160 & 160 \\
& $(160,170)$ & $(110,160)$ & $(165,170)$ & $(170,170)$ & $(160,170)$ & $(165,170)$ & $(160,170)$ & $(110,170)$ & $(170,170)$ \\
period 8 & 170 & 170 & 170 & 110 & 170 & 170 & 115 & 170 & 160 \\
& $(170,170)$ & $(170,170)$ & $(110,170)$ & $(170,170)$ & $(110,170)$ & $(115,160)$ & $(160,170)$ & $(170,170)$ & $(115,170)$ \\
period 9 & 170 & 170 & 170 & 110 & 170 & 170 & 120 & 160 & 160 \\
& $(170,170)$ & $(110,160)$ & $(170,170)$ & $(160,170)$ & $(170,170)$ & $(120,160)$ & $(160,170)$ & $(120,170)$ & $(110,170)$ \\
period 10 & 110 & 170 & 150 & 170 & 170 & 170 & 170 & 160 & 160 \\
& $(160,170)$ & $(150,170)$ & $(170,170)$ & $(160,170)$ & $(160,170)$ & $(150,170)$ & $(110,160)$ & $(170,170)$ & $(110,170)$ \\
\hline
\end{tabular}

Session 2: Effort Decisions (Others' Decisions) for Effort Cost $c=0.60$

\begin{tabular}{|c|c|c|c|c|c|c|c|c|c|}
\hline & subject 1 & subject 2 & subject 3 & subject 4 & subject 6 & subject 7 & subject 8 & subject 9 & subject 10 \\
\hline period 1 & $\begin{array}{c}110 \\
(146,150)\end{array}$ & $\begin{array}{c}117 \\
(110,170)\end{array}$ & $\begin{array}{c}170 \\
(110,117)\end{array}$ & $\begin{array}{c}112 \\
(110,140)\end{array}$ & $\begin{array}{c}155 \\
(110,146)\end{array}$ & $\begin{array}{c}146 \\
(110,150)\end{array}$ & $\begin{array}{c}110 \\
(117,170)\end{array}$ & $\begin{array}{c}140 \\
(112,110)\end{array}$ & $\begin{array}{c}110 \\
(112,140)\end{array}$ \\
\hline period 2 & $\begin{array}{c}110 \\
(110,110)\end{array}$ & $\begin{array}{c}110 \\
(110,110)\end{array}$ & $\begin{array}{c}110 \\
(110,110)\end{array}$ & $\begin{array}{c}110 \\
(110,133)\end{array}$ & $\begin{array}{c}120 \\
(110,120)\end{array}$ & $\begin{array}{c}133 \\
(110,110)\end{array}$ & $\begin{array}{c}110 \\
(120,120)\end{array}$ & $\begin{array}{c}120 \\
(110,120)\end{array}$ & $\begin{array}{c}110 \\
(110,133)\end{array}$ \\
\hline period 3 & $\begin{array}{c}110 \\
(110,110)\end{array}$ & $\begin{array}{c}112 \\
(115,167)\end{array}$ & $\begin{array}{c}110 \\
(110,115)\end{array}$ & $\begin{array}{c}110 \\
(110,110)\end{array}$ & $\begin{array}{c}115 \\
(112,167)\end{array}$ & $\begin{array}{c}167 \\
(112,115)\end{array}$ & $\begin{array}{c}110 \\
(110,115)\end{array}$ & $\begin{array}{c}115 \\
(110,110)\end{array}$ & $\begin{array}{c}110 \\
(110,110)\end{array}$ \\
\hline period 4 & $\begin{array}{c}110 \\
(110,150)\end{array}$ & $\begin{array}{c}150 \\
(110,110)\end{array}$ & $\begin{array}{c}110 \\
(110,150)\end{array}$ & $(128,145)$ & $\begin{array}{c}145 \\
(110,128)\end{array}$ & $\begin{array}{c}128 \\
(110,145)\end{array}$ & $\begin{array}{c}110 \\
(110,110)\end{array}$ & $\begin{array}{c}110 \\
(110,110)\end{array}$ & $\begin{array}{c}110 \\
(110,110)\end{array}$ \\
\hline period 5 & $\begin{array}{c}110 \\
(110,145)\end{array}$ & $\begin{array}{c}113 \\
(117,110)\end{array}$ & $\begin{array}{c}110 \\
(110,145)\end{array}$ & $\begin{array}{c}110 \\
(110,110)\end{array}$ & $\begin{array}{c}145 \\
(110,110)\end{array}$ & $\begin{array}{c}117 \\
(113,110)\end{array}$ & $\begin{array}{c}110 \\
(110,110)\end{array}$ & $\begin{array}{c}110 \\
(110,110)\end{array}$ & $\begin{array}{c}110 \\
(113,117)\end{array}$ \\
\hline period 6 & $\begin{array}{c}110 \\
(110,111)\end{array}$ & $\begin{array}{c}111 \\
(110,110)\end{array}$ & $\begin{array}{c}110 \\
(110,110)\end{array}$ & $\begin{array}{c}110 \\
(110,110)\end{array}$ & $\begin{array}{c}111 \\
(110,125)\end{array}$ & $\begin{array}{c}125 \\
(111,110)\end{array}$ & $\begin{array}{c}110 \\
(110,110)\end{array}$ & $\begin{array}{c}110 \\
(110,111)\end{array}$ & $\begin{array}{c}110 \\
(111,125)\end{array}$ \\
\hline period 7 & $\begin{array}{c}110 \\
(110,141)\end{array}$ & $\begin{array}{c}110 \\
(110,110)\end{array}$ & $\begin{array}{c}110 \\
(110,110)\end{array}$ & $\begin{array}{c}110 \\
(110,110)\end{array}$ & $\begin{array}{c}120 \\
(110,110)\end{array}$ & $\begin{array}{c}141 \\
(110,110)\end{array}$ & $\begin{array}{c}110 \\
(110,120)\end{array}$ & $\begin{array}{c}110 \\
(110,120)\end{array}$ & $\begin{array}{c}110 \\
(110,141)\end{array}$ \\
\hline period 8 & $\begin{array}{c}110 \\
(110,110)\end{array}$ & $\begin{array}{c}115 \\
(112,115)\end{array}$ & $\begin{array}{c}110 \\
(110,110)\end{array}$ & $\begin{array}{c}110 \\
(110,110)\end{array}$ & $\begin{array}{c}115 \\
(112,115)\end{array}$ & $\begin{array}{c}112 \\
(115,115)\end{array}$ & $\begin{array}{c}110 \\
(110,110)\end{array}$ & $\begin{array}{c}110 \\
(110,110)\end{array}$ & $\begin{array}{c}110 \\
(110,110)\end{array}$ \\
\hline period 9 & $\begin{array}{c}110 \\
(110,110)\end{array}$ & $\begin{array}{c}120 \\
(117,121)\end{array}$ & $\begin{array}{c}110 \\
(110,110)\end{array}$ & $\begin{array}{c}110 \\
(110,110)\end{array}$ & $\begin{array}{c}117 \\
(120,121)\end{array}$ & $\begin{array}{c}121 \\
(117,120)\end{array}$ & $\begin{array}{c}110 \\
(110,110)\end{array}$ & $\begin{array}{c}110 \\
(110,110)\end{array}$ & $\begin{array}{c}110 \\
(110,110)\end{array}$ \\
\hline period 10 & $\begin{array}{c}110 \\
(110,125)\end{array}$ & $\begin{array}{c}118 \\
(110,118)\end{array}$ & $\begin{array}{c}110 \\
(110,125)\end{array}$ & $\begin{array}{c}110 \\
(110,110)\end{array}$ & $\begin{array}{c}118 \\
(110,118)\end{array}$ & $\begin{array}{c}125 \\
(110,110)\end{array}$ & $\begin{array}{c}110 \\
(110,110)\end{array}$ & $\begin{array}{c}110 \\
(110,110)\end{array}$ & $\begin{array}{c}110 \\
(118,118)\end{array}$ \\
\hline
\end{tabular}


Session 3: Effort Decisions (Others' Decisions) for Effort Cost $c=0.40$

\begin{tabular}{|c|c|c|c|c|c|c|c|c|c|}
\hline & & & & & & & & & \\
\hline & $\begin{array}{c}150 \\
(169,110)\end{array}$ & $50,169)$ & $110,110)$ & $\begin{array}{c}110 \\
(140,110)\end{array}$ & $\begin{array}{c}110 \\
(110,170)\end{array}$ & 110) & $\begin{array}{c}169 \\
(110,150)\end{array}$ & 70) & 10) \\
\hline & $\begin{array}{r}110 \\
(140,\end{array}$ & $\begin{array}{c}111 \\
170,170)\end{array}$ & $\begin{array}{c}170 \\
111,170)\end{array}$ & $\begin{array}{c}110 \\
(111,170)\end{array}$ & $\begin{array}{c}170 \\
(111,170)\end{array}$ & $\begin{array}{c}150 \\
(110,140)\end{array}$ & (110, & (110, & (110, \\
\hline & $\begin{array}{r}110 \\
(110,11\end{array}$ & $\begin{array}{c}113 \\
(110,110)\end{array}$ & $\begin{array}{c}170 \\
(110,140)\end{array}$ & $\begin{array}{c}110 \\
(110,113)\end{array}$ & $\begin{array}{c}145 \\
(140,150)\end{array}$ & $\begin{array}{c}140 \\
(110,170)\end{array}$ & $\begin{array}{r}15 \\
(140,\end{array}$ & $\begin{array}{r}11 \\
(140,\end{array}$ & $\begin{array}{r}14 \\
(145,\end{array}$ \\
\hline & $\begin{array}{r}110 \\
(140,\end{array}$ & $\begin{array}{c}170 \\
70,170)\end{array}$ & $\begin{array}{r}17 \\
(170,\end{array}$ & $\begin{array}{c}169 \\
(110,140)\end{array}$ & $\begin{array}{l}17 \\
(170\end{array}$ & $\begin{array}{r}14 \\
(110,\end{array}$ & $\begin{array}{r}1 \\
(110,\end{array}$ & $\begin{array}{r}11 \\
(110,\end{array}$ & $\begin{array}{r}1 \\
(110,\end{array}$ \\
\hline & $\begin{array}{c}110 \\
(110,155)\end{array}$ & $\begin{array}{c}120 \\
(140,170)\end{array}$ & $\begin{array}{c}170 \\
(120,140)\end{array}$ & $\begin{array}{c}170 \\
(110,130)\end{array}$ & $\begin{array}{c}110 \\
(110,155)\end{array}$ & $\begin{array}{c}130 \\
(110,170)\end{array}$ & $\begin{array}{c}155 \\
(110,110)\end{array}$ & $\begin{array}{r}11( \\
(130,\end{array}$ & $\begin{array}{r}14 \\
(120,\end{array}$ \\
\hline & $\begin{array}{c}110 \\
(130,140)\end{array}$ & $\begin{array}{c}160 \\
(170,140)\end{array}$ & $\begin{array}{c}170 \\
(145,170)\end{array}$ & $\begin{array}{c}170 \\
(160,140)\end{array}$ & $\begin{array}{c}170 \\
(145,170)\end{array}$ & $(110,140)$ & $\begin{array}{c}145 \\
(170,170)\end{array}$ & $\begin{array}{c}140 \\
(160,170)\end{array}$ & $\begin{array}{c}140 \\
(110,130)\end{array}$ \\
\hline & $\begin{array}{c}110 \\
(110,145)\end{array}$ & $\begin{array}{c}110 \\
(110,170)\end{array}$ & $\begin{array}{c}170 \\
(110,170)\end{array}$ & $\begin{array}{c}110 \\
(170,170)\end{array}$ & $\begin{array}{c}170 \\
(110,170)\end{array}$ & $\begin{array}{c}110 \\
(110,145)\end{array}$ & $\begin{array}{c}145 \\
(110,110)\end{array}$ & $\begin{array}{c}170 \\
(110,110)\end{array}$ & $\begin{array}{r}11 \\
(110,\end{array}$ \\
\hline & $\begin{array}{c}110 \\
(110,170)\end{array}$ & $\begin{array}{c}170 \\
(154,170)\end{array}$ & $\begin{array}{c}170 \\
(110,110)\end{array}$ & $\begin{array}{c}154 \\
(170,170)\end{array}$ & $\begin{array}{c}170 \\
(154,170)\end{array}$ & $\begin{array}{c}130 \\
(110,140)\end{array}$ & $\begin{array}{c}110 \\
(110,170)\end{array}$ & $\begin{array}{c}140 \\
(130,110)\end{array}$ & $\begin{array}{c}110 \\
(130,140)\end{array}$ \\
\hline & $\begin{array}{c}110 \\
(110,140)\end{array}$ & $\begin{array}{c}170 \\
(170,140)\end{array}$ & $\begin{array}{c}170 \\
(110,140)\end{array}$ & $\begin{array}{c}170 \\
(170,140)\end{array}$ & $\begin{array}{c}110 \\
(110,140)\end{array}$ & $\begin{array}{c}140 \\
(110,110)\end{array}$ & $\begin{array}{c}110 \\
(140,170)\end{array}$ & $\begin{array}{c}140 \\
(170,170)\end{array}$ & $\begin{array}{c}140 \\
(110,170)\end{array}$ \\
\hline period 10 & $\begin{array}{c}110 \\
(110,170)\end{array}$ & $\begin{array}{c}170 \\
110,110)\end{array}$ & $\begin{array}{c}110 \\
(110,140)\end{array}$ & $\begin{array}{c}110 \\
(110,170)\end{array}$ & $\begin{array}{c}170 \\
(110,110)\end{array}$ & $\begin{array}{c}110 \\
(110,140)\end{array}$ & $\begin{array}{c}110 \\
(110,170)\end{array}$ & $\begin{array}{c}140 \\
(110,110)\end{array}$ & $\begin{array}{c}110 \\
(110,140)\end{array}$ \\
\hline
\end{tabular}

Session 4: Effort Decisions (Others' Decisions) for Effort Cost $c=0.40$

\begin{tabular}{|c|c|c|c|c|c|c|c|c|c|}
\hline & & & & & & & & & \\
\hline period 1 & $\begin{array}{c}155 \\
(170,110)\end{array}$ & $\begin{array}{c}110 \\
(155,170)\end{array}$ & $\begin{array}{c}160 \\
(168,125)\end{array}$ & $\begin{array}{c}125 \\
(160,168)\end{array}$ & $\begin{array}{c}150 \\
(110,150)\end{array}$ & $\begin{array}{c}168 \\
(125,160)\end{array}$ & $\begin{array}{c}170 \\
(110,155)\end{array}$ & $\begin{array}{c}150 \\
(110,150)\end{array}$ & $\begin{array}{c}110 \\
(150,150)\end{array}$ \\
\hline period 2 & $\begin{array}{c}145 \\
(110,169)\end{array}$ & $\begin{array}{c}110 \\
(145,169)\end{array}$ & $\begin{array}{c}166 \\
(130,160)\end{array}$ & $\begin{array}{c}130 \\
(160,166)\end{array}$ & $\begin{array}{c}110 \\
(110,170)\end{array}$ & $\begin{array}{c}169 \\
(110,145)\end{array}$ & $\begin{array}{c}170 \\
(110,110)\end{array}$ & $\begin{array}{c}160 \\
(130,166)\end{array}$ & $\begin{array}{c}110 \\
(110,170)\end{array}$ \\
\hline period 3 & $\begin{array}{c}160 \\
(120,169)\end{array}$ & $\begin{array}{c}110 \\
(140,150)\end{array}$ & $\begin{array}{c}170 \\
(110,160)\end{array}$ & $\begin{array}{c}160 \\
(110,170)\end{array}$ & $\begin{array}{c}150 \\
(140,110)\end{array}$ & $\begin{array}{c}169 \\
(120,160)\end{array}$ & $\begin{array}{c}110 \\
(160,170)\end{array}$ & $\begin{array}{c}140 \\
(110,150)\end{array}$ & $\begin{array}{c}120 \\
(160,169)\end{array}$ \\
\hline period 4 & $\begin{array}{c}160 \\
(150,145)\end{array}$ & $\begin{array}{c}110 \\
(120,160)\end{array}$ & $\begin{array}{c}162 \\
(110,115)\end{array}$ & $\begin{array}{c}110 \\
(115,162)\end{array}$ & $\begin{array}{c}150 \\
(145,160)\end{array}$ & $\begin{array}{c}160 \\
(110,120)\end{array}$ & $\begin{array}{c}145 \\
(150,160)\end{array}$ & $\begin{array}{c}115 \\
(110,162)\end{array}$ & $\begin{array}{c}120 \\
(110,160)\end{array}$ \\
\hline period 5 & $\begin{array}{c}160 \\
(160,161)\end{array}$ & $\begin{array}{c}110 \\
(160,155)\end{array}$ & $\begin{array}{c}160 \\
(160,161)\end{array}$ & $\begin{array}{c}161 \\
(160,160)\end{array}$ & $\begin{array}{c}150 \\
(120,145)\end{array}$ & $\begin{array}{c}160 \\
(110,155)\end{array}$ & $\begin{array}{c}145 \\
(120,150)\end{array}$ & $\begin{array}{c}155 \\
(110,160)\end{array}$ & $\begin{array}{c}120 \\
(145,150)\end{array}$ \\
\hline period 6 & $\begin{array}{c}160 \\
(162,169)\end{array}$ & $\begin{array}{c}110 \\
(120,150)\end{array}$ & $\begin{array}{c}162 \\
(160,169)\end{array}$ & $\begin{array}{c}145 \\
(160,145)\end{array}$ & $\begin{array}{c}150 \\
(110,120)\end{array}$ & $\begin{array}{c}169 \\
(160,162)\end{array}$ & $\begin{array}{c}145 \\
(145,160)\end{array}$ & $\begin{array}{c}160 \\
(145,145)\end{array}$ & $\begin{array}{c}120 \\
(110,150)\end{array}$ \\
\hline period 7 & $\begin{array}{c}140 \\
(110,170)\end{array}$ & $\begin{array}{c}110 \\
(120,169)\end{array}$ & $\begin{array}{c}170 \\
(110,140)\end{array}$ & $\begin{array}{c}110 \\
(140,170)\end{array}$ & $\begin{array}{c}150 \\
(145,150)\end{array}$ & $\begin{array}{c}169 \\
(110,120)\end{array}$ & $\begin{array}{c}145 \\
(150,150)\end{array}$ & $\begin{array}{c}150 \\
(145,150)\end{array}$ & $\begin{array}{c}120 \\
(110,169)\end{array}$ \\
\hline period 8 & $\begin{array}{c}160 \\
(120,140)\end{array}$ & $\begin{array}{c}140 \\
(141,165)\end{array}$ & $\begin{array}{c}165 \\
(140,141)\end{array}$ & $\begin{array}{c}141 \\
(140,165)\end{array}$ & $\begin{array}{c}125 \\
(140,169)\end{array}$ & $\begin{array}{c}169 \\
(125,140)\end{array}$ & $\begin{array}{c}145 \\
(120,160)\end{array}$ & $\begin{array}{c}140 \\
(125,169)\end{array}$ & $\begin{array}{c}120 \\
(145,160)\end{array}$ \\
\hline period 9 & $\begin{array}{c}150 \\
(110,110)\end{array}$ & $\begin{array}{c}110 \\
(110,150)\end{array}$ & $\begin{array}{c}160 \\
(120,155)\end{array}$ & $\begin{array}{c}110 \\
(125,160)\end{array}$ & $\begin{array}{c}125 \\
(110,160)\end{array}$ & $\begin{array}{c}160 \\
(110,125)\end{array}$ & $\begin{array}{c}110 \\
(110,150)\end{array}$ & $\begin{array}{c}155 \\
(120,160)\end{array}$ & $\begin{array}{c}120 \\
(155,160)\end{array}$ \\
\hline period 10 & $\begin{array}{c}150 \\
(110,145)\end{array}$ & $\begin{array}{c}110 \\
(150,164)\end{array}$ & $\begin{array}{c}164 \\
(110,150)\end{array}$ & $\begin{array}{c}110 \\
(145,150)\end{array}$ & $\begin{array}{c}125 \\
(110,160)\end{array}$ & $\begin{array}{c}160 \\
(110,125)\end{array}$ & $\begin{array}{c}145 \\
(110,150)\end{array}$ & $\begin{array}{c}150 \\
(110,164)\end{array}$ & $\begin{array}{c}110 \\
(125,160)\end{array}$ \\
\hline
\end{tabular}




\section{Appendix D: Data for The Three Person Minimum-Effort Game}

Session 1: Effort Decisions (Top) and Others' Decisions (Bottom) for Effort Cost $c=0.50$

\begin{tabular}{cccccccccccc}
\hline \hline subject 1 & subject 2 & subject 3 & subject 4 & subject 5 & subject 6 & subject 7 & subject 8 & subject 9 & subject 10 & subject 11 & subject 12 \\
\hline 125 & 125 & 125 & 170 & 130 & 170 & 170 & 170 & 140 & 140 & 130 & 110 \\
110,140 & 140,170 & 130,170 & 125,130 & 170,170 & 125,140 & 130,170 & 130,170 & 110,125 & 125,170 & 125,170 & 125,140 \\
110 & 110 & 150.5 & 130 & 150 & 170 & 170 & 170 & 110 & 150 & 150 & 110 \\
110,170 & 170,170 & 150,150 & 150,170 & $150.5,150$ & 110,110 & 110,110 & 130,150 & 110,170 & $150,150.5$ & 130,170 & 110,170 \\
150 & 110 & 144.9 & 150 & 155 & 170 & 110 & 170 & 110 & 160 & 140 & 110 \\
110,140 & 110,160 & 110,155 & 170,170 & $110,144.9$ & 150,170 & 110,160 & 150,170 & 140,150 & 110,110 & 110,150 & $144.9,155$ \\
150 & 170 & 115 & 170 & 150 & 170 & 110 & 170 & 110 & 170 & 110 & 110 \\
110,110 & 170,170 & 110,170 & 110,150 & 110,170 & 170,170 & 110,150 & 170,170 & 150,170 & 110,115 & 115,170 & 110,150 \\
110 & 170 & 110 & 150 & 110 & 170 & 120 & 170 & 110 & 140 & 140 & 110 \\
110,170 & 110,120 & 110,150 & 110,110 & 120,170 & 110,110 & 110,170 & 140,140 & 110,170 & 140,170 & 140,170 & 110,150 \\
120 & 140 & 120 & 140 & 120 & 170 & 110 & 150 & 110 & 135 & 170 & 110 \\
130,170 & 110,140 & 110,110 & 110,140 & 150,170 & 120,135 & 110,120 & 120,170 & 110,170 & 120,170 & 120,150 & 110,120 \\
130 & 110 & 112 & 130 & 150 & 170 & 110 & 170 & 110 & 140 & 170 & 110 \\
110,120 & 170,140 & 110,130 & 110,170 & 110,170 & 110,150 & 130,170 & 110,140 & 140,140 & 110,170 & 110,130 & 150,170 \\
120 & 120 & 130 & 120 & 130 & 140 & 120 & 170 & 110 & 130 & 110 & 110 \\
120,130 & 130,170 & 120,120 & 120,130 & 110,170 & 110,110 & 110,130 & 120,130 & 112,130 & 120,170 & 120,130 & 110,140 \\
130 & 125 & 120 & 130 & 120 & 140 & 120 & 170 & 110 & 140 & 150 & 110 \\
110,140 & 120,120 & 120,125 & 120,125 & 140,150 & 110,130 & 110,170 & 110,120 & 110,140 & 120,150 & 140,120 & 120,170 \\
110 & 125 & 119.9 & 125 & 170 & 140 & 110 & 130 & 110 & 125 & 130 & 110 \\
130,140 & 130,170 & 110,110 & 125,110 & 125,130 & 110,130 & $110,119.9$ & 110,140 & $110,119.9$ & 110,125 & 125,170 & 125,125 \\
\hline
\end{tabular}

Session 1: Effort Decisions (Top) and Others' Decisions (Bottom) for Effort Cost $c=0.10$

\begin{tabular}{cccccccccccc}
\hline \hline subject & subject & subject & subject & subject & subject & subject & subject & subject & subject & subject & subject \\
1 & 2 & 3 & 4 & 5 & 6 & 7 & 8 & 9 & 10 & 11 & 12 \\
\hline 168 & 159.4 & 170 & 159 & 170 & 110 & 150 & 125 & 135.5 & 110 & 160 & 110 \\
110,150 & 125,170 & $159.4,125$ & 110,160 & $110,135.5$ & 150,168 & 110,168 & $159.4,170$ & 110,170 & $135.5,170$ & 110,159 & 159,160 \\
110 & 164 & 170 & 150 & 170 & 170 & 170 & 160 & 168 & 135.5 & 145 & 169.9 \\
164,170 & 110,170 & $135.5,170$ & 145,160 & $169.9,168$ & 110,164 & $135.5,170$ & 145,150 & $169.9,170$ & 170,170 & 150,160 & 168,170 \\
170 & 164 & 170 & 140 & 170 & 170 & 170 & 150 & 168 & 170 & 145 & 170 \\
170,170 & 168,170 & 140,145 & 145,170 & 150,170 & 164,168 & 150,170 & 170,170 & 164,170 & 170,170 & 140,170 & 170,170 \\
170 & 164 & 170 & 145 & 170 & 170 & 170 & 160 & 168 & 170 & 170 & 169 \\
145,170 & 168,199 & 170,170 & 170,170 & 160,170 & 170,170 & 170,170 & 170,170 & 164,169 & 145,170 & 160,170 & 164,168 \\
170 & 164 & 170 & 170 & 170 & 170 & 170 & 170 & 169 & 170 & 170 & 157 \\
170,170 & 170,170 & 164,170 & 157,169 & 170,170 & 170,170 & 170,170 & 170,170 & 157,170 & 170,170 & 164,170 & 169,170 \\
170 & 170 & 170 & 170 & 170 & 170 & 170 & 170 & 167.5 & 170 & 170 & 170 \\
170,170 & 170,170 & 170,170 & $167.5,170$ & $167.5,170$ & 170,170 & 170,170 & 170,170 & 170,170 & 170,170 & 170,170 & 170,170 \\
170 & 170 & 170 & 170 & 170 & 170 & 170 & 170 & 170 & 170 & 170 & 170 \\
170,170 & 170,170 & 170,170 & 170,170 & 170,170 & 170,170 & 170,170 & 170,170 & 170,170 & 170,170 & 170,170 & 170,170 \\
170 & 170 & 170 & 170 & 170 & 170 & 170 & 170 & 170 & 170 & 170 & 170 \\
170,170 & 170,170 & 170,170 & 170,170 & 170,170 & 170,170 & 170,170 & 170,170 & 170,170 & 170,170 & 170,170 & 170,170 \\
170 & 170 & 170 & 170 & 170 & 170 & 170 & 170 & 170 & 170 & 170 & 170 \\
170,170 & 170,170 & 170,170 & 170,170 & 170,170 & 170,170 & 170,170 & 170,170 & 170,170 & 170,170 & 170,170 & 170,170 \\
170 & 170 & 170 & 170 & 170 & 170 & 170 & 170 & 170 & 170 & 170 & 170 \\
170,170 & 170,170 & 170,170 & 170,170 & 170,170 & 170,170 & 170,170 & 170,170 & 170,170 & 170,170 & 170,170 & 170,170 \\
\hline
\end{tabular}




\section{References}

Anderson, Simon P., Jacob K. Goeree, and Charles A. Holt (1997a) "Stochastic Game Theory: Adjustment and Equilibrium with Bounded Rationality," working paper, University of Virginia.

Anderson, Simon P., Jacob K. Goeree, and Charles A. Holt (1997b) "Minimum-Effort Coordination Games: An Equilibrium Analysis of Bounded Rationality," working paper, University of Virginia.

Battalio, Raymond C., Larry Samuelson, and John Van Huyck (1997) "Risk Dominance, Payoff Dominance, and Probabilistic Choice Learning," working paper, Texas A\&M University.

Bryant, John (1983) "A Simple Rational Expectations Keynes-Type Model," Quarterly Journal of Economics, 98, 525-528.

Camerer, Colin and Teck-Hua Ho (1999) "Experience Weighted Attraction Learning in NormalForm Games," forthcoming in Econometrica.

Capra, C. Monica, Jacob K. Goeree, Rosario Gomez, and Charles A. Holt (1999) "Anomalous Behavior in a Traveler's Dilemma?" American Economic Review, 89(3), June, 678-690.

Carlsson, Hans and Eric van Damme (1993) "Global Games and Equilibrium Selection," Econometrica, 61(5), September, 989-1018.

Carlsson, Hans and Mattias Ganslandt (1998) "Noisy Equilibrium Selection in Coordination Games," Economics Letters, 60, 23-34.

Cooper, Russell, Douglas V. DeJong, Robert Forsythe, and Thomas W. Ross (1992) "Communication in Coordination Games," Quarterly Journal of Economics, 107, 739-771.

Cooper, Russell, and Andrew John (1988) "Coordinating Coordination Failures in Keynesian Models," The Quarterly Journal of Economics, 103, 441-464.

Crawford, Vincent P. (1991) "An 'Evolutionary' Interpretation of Van Huyck, Battalio and Beil's Experimental Results on Coordination," Games and Economic Behavior, 3, 25-59.

Crawford, Vincent P. (1995) "Adaptive Dynamics in Coordination Games," Econometrica, 63, 103-144.

Goeree, Jacob K. and Charles A. Holt (1999) "Stochastic Game Theory: For Playing Games, Not Just for Doing Theory," forthcoming in the Proceedings of the National Academy of Sciences.

Harsanyi, John C. and Reinhard Selten (1988) A General Theory of Equilibrium Selection in Games, Cambridge, Mass.: MIT Press. 
Harsanyi, John C.(1995) "A New Theory of Equilibrium Selection for Games with Complete Information," Games and Economic Behavior, 8, 91-122.

Knez, Marc, and Colin Camerer (1994) "Creating Expectational Assets in the Laboratory: Coordination in 'Weakest-Link' Games," Strategic Management Journal, 15, 101-119.

Kandori, Michihiro, George Mailath, and Rafael Rob (1993) "Learning, Mutation, and Long Run Equilibria in Games," Econometrica, 61(1), 29-56.

McKelvey, Richard D. and Thomas R. Palfrey (1995) "Quantal Response Equilibria for Normal Form Games," Games and Economic Behavior, 10, 6-38.

Monderer, Dov, and Lloyd S. Shapley (1996) "Potential Games," Games and Economic Behavior, $14,124-143$.

Ochs, Jack (1995) "Coordination Problems," in J. Kagel and A. Roth (eds.), Handbook of Experimental Economics, Princeton: Princeton University Press, 1995, 195-249.

Romer, David (1996) Advanced Macroeconomics, New York: McGraw-Hill.

Rosenthal, Robert W. (1973) "A Class of Games Possessing Pure-Strategy Nash Equilibria," International Journal of Game Theory, 2, 65-67.

Rosenthal, Robert W. (1989) "A Bounded Rationality Approach to the Study of Noncooperative Games," International Journal of Game Theory, 18, 273-292.

Straub, Paul G. (1995) "Risk Dominance and Coordination Failures in Static Games," Quarterly Review of Economics and Finance, 35(4), Winter 1995, 339-363.

Van Huyck, John B., Raymond C. Battalio, and Richard O. Beil (1990) "Tacit Coordination Games, Strategic Uncertainty, and Coordination Failure," American Economic Review, 80, 234-248.

Van Huyck, John B., Raymond C. Battalio, and Richard O. Beil (1991) "Strategic Uncertainty, Equilibrium Selection, and Coordination Failure in Average Opinion Games," Quarterly Journal of Economics, 91, 885-910.

Van Huyck, John B., Raymond C. Battalio, and Frederick Rankin (1997) "On the Origin of Convention: Evidence from Coordination Games," working paper, Texas A\&M University.

Young, Peyton (1993) "The Evolution of Conventions," Econometrica, 61, 57-84. 